\title{
Computational Thermodynamic Calculations: FactSage from CALPHAD Thermodynamic Database to Virtual Process Simulation
}

\begin{abstract}
IN-HO JUNG and MARIE-ALINE VAN ENDE
The CALPHAD-type computational thermodynamic databases have been developed since 1970. Several commercial computational thermodynamic software equipped with comprehensive and accurate thermodynamic databases and fast Gibbs energy minimization routine are widely used in the design of new materials and the optimization of materials processing. In this study, the FactSage software, which is the most frequently accessed software in high temperature materials processing, is briefly overviewed. The current databases and on-going directions of the thermodynamic database development are discussed. Application examples of FactSage thermodynamics databases to steel processing from the iron ore sintering process to the final metallic coating process are presented. Lastly, the most recent and future application of the FactSage thermodynamic databases to virtual steelmaking process simulations for the so-called industry 4.0 (smart factory) is highlighted.
\end{abstract}

https://doi.org/10.1007/s11663-020-01908-7

(c) The Minerals, Metals \& Materials Society and ASM International 2020

\section{INTRODUCTION}

NowADAYS, thermodynamic calculations using various commercial software are very popular in materials science and engineering fields. All thermodynamic software packages include thermodynamic databases, which are developed based on the so-called CALculation of PHAse Diagram (CALPHAD) methodology. The CALPHAD methodology was introduced in the 1960s by Larry Kaufman and the essence is the optimization of the Gibbs energy functions to reproduce the known phase diagrams, and utilize it to make the prediction of unknown phase equilibria. ${ }^{[1,2]}$

In the thermodynamic optimization (modeling) based on the CALPHAD method, all available thermodynamic and phase equilibrium data for the system are critically and simultaneously evaluated in order to obtain one self-consistent set of model equations for the Gibbs energies which best reproduce the data for all phases as functions of temperature and composition. The thermodynamic models with optimized parameters for low-order (binary and ternary) subsystems can be used to provide good estimates for unexplored phase

IN-HO JUNG and MARIE-ALINE VAN ENDE are with the Department of Materials Science and Engineering, and Research Institute of Advanced Materials (RIAM), Seoul National University, 1 Gwanak-ro, Gwanak-gu, Seoul 08826, South Korea. Contact e-mail: in-ho.jung@snu.ac.kr

Manuscript submitted March 21, 2020.

Article published online August 3, 2020. diagram and thermodynamic properties in low-order or high-order systems. In particular, because industrial material processes often involve complex chemical reactions which have not been studied previously, thermodynamic software that can predict phase equilibria in complex multicomponent systems is a very practical tool in the optimization of material processes. Of course, the software can be well applied to the materials design.

Several commercial thermodynamic software packages have been developed since the 1970s: FactSage (www.factsage.com) and ThermoCalc (www.thermoca lc.com) are two packages which have the longest history of development and the widest range of application users. MTDATA (National Physical Laboratory, UK), Pandat (www.computherm.com), MatCalc (www.matcalc-engineering.com), and MPE (CSIRO, Australia) are other software packages used more and more recently in specific materials development areas. The applications of thermodynamic software to steelmaking ${ }^{[3]}$ and pyrometallurgical processes $^{[4]}$ have been reviewed several times.

In the present study, the history and thermodynamic database development of the FactSage software package, which is the most popular thermodynamic software in high temperature materials processing such as steelmaking, non-ferrous making, glassmaking, combustions, recycling, etc., will be overviewed. Many thermodynamic calculations will be presented for steel processing to demonstrate a wide range of applicability of the thermodynamic database in materials processing. The evolution of thermodynamic calculations from a 
simple one-system calculation to virtual pyrometallurgical process simulation will show the future of computational thermodynamics.

\section{FACTSAGE: HISTORY AND DEVELOPMENT}

\section{A. History of FactSage}

FactSage is a commercially available software which was introduced in 2001 as the fusion of the $\mathrm{F}^{*} \mathrm{~A}^{*} \mathrm{C}^{*} \mathrm{~T} /$ FACT-Win (Thermfact, Canada) and ChemSage (GTT-Technology, Germany) thermochemical packages. $\mathrm{F}^{*} \mathrm{~A} \mathrm{C}^{*} \mathrm{~T}$ system originated back to 1976 . Until the 1990s, the main application field of the FactSage system was high temperature pyrometallurgical processes. Since 2000s, many new thermodynamic databases for steel, light alloys, copper, silicon, nuclear materials, aqueous solution, etc. have been developed. Their capabilities have been greatly expanded to cover a wide range of material science and engineering applications. Recent development of FactSage can be found elsewhere. ${ }^{[5]}$

In general, the usage of thermodynamic software packages like FactSage and ThermoCalc has accelerated since 2000s. FactSage has been cited in total 5140 times in open source publication since year 2000 (searched from SCOPUS; www.scopus.com), and the main citated research areas are metallurgy, ceramics, and energy and fuel combustion, as shown in Figure 1. It should be noted that the journal where FactSage is most cited is Metallurgical and Materials Transaction B which covers pyrometallurgical processes, and general high temperature materials processing.
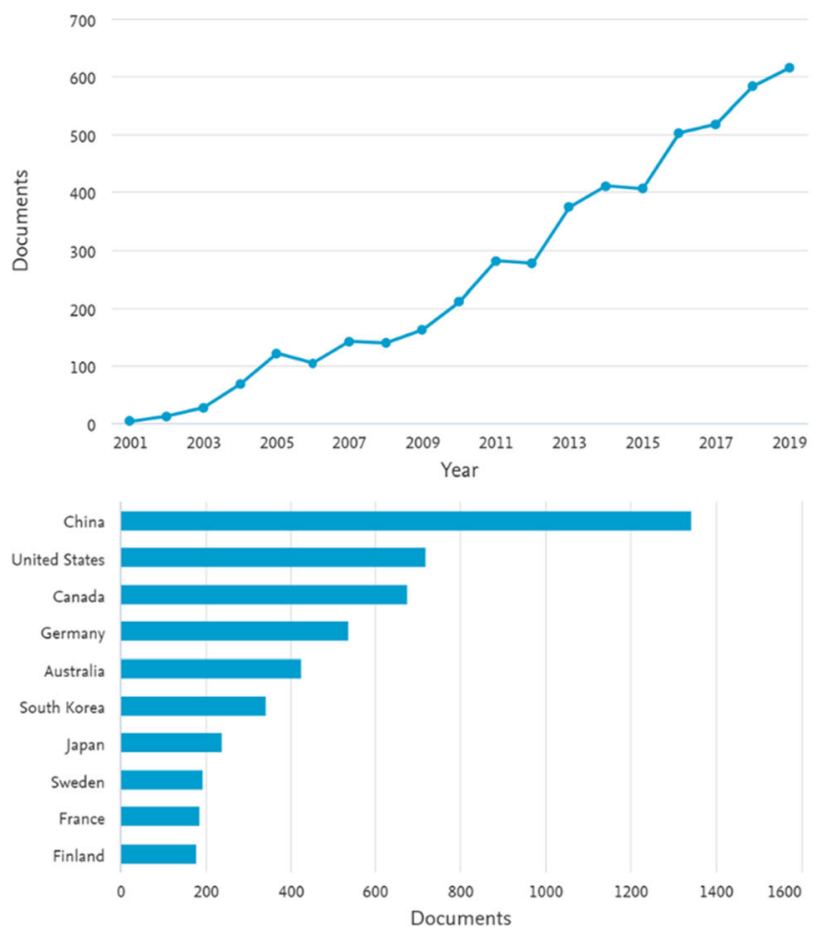

In order to facilitate the usage of computational thermodynamics database in materials science and engineering fields, the education of computational thermodynamics and regular software training are important. There have been FactSage workshops to train graduate students and researchers in industry in Canada, China, Korea, Germany, and many other countries. The workshops in Korea, for example, have been held since 2003, and trained more than 1000 graduate students and researchers in Korea. This certainly boosts the usage of thermodynamic calculations in material design and process optimization.

\section{B. Thermodynamic Models and Thermodynamic Databases}

Two important prerequisites for accurate thermodynamic calculations are the accuracy of the algorithm that minimizes the total Gibbs energy of a system with a given set of constraints, and the availability of accurate thermodynamic database covering the given system of interest.

FactSage uses the ChemSage Gibbs energy minimization routine. The special ChemSage Fortran routine embedded in FactSage can handle complex thermodynamic calculations involving up to 40 elements and a maximum of 200 solutions and 1500 stoichiometric phases per equilibrium calculation. FactSage can handle elemental input amounts down to $10^{-61} \mathrm{~mol}$ in its thermodynamic calculations and provide precise calculation results down to a cutoff limit of $10^{-75} \mathrm{~mol}$. Therefore, FactSage is well suited to perform
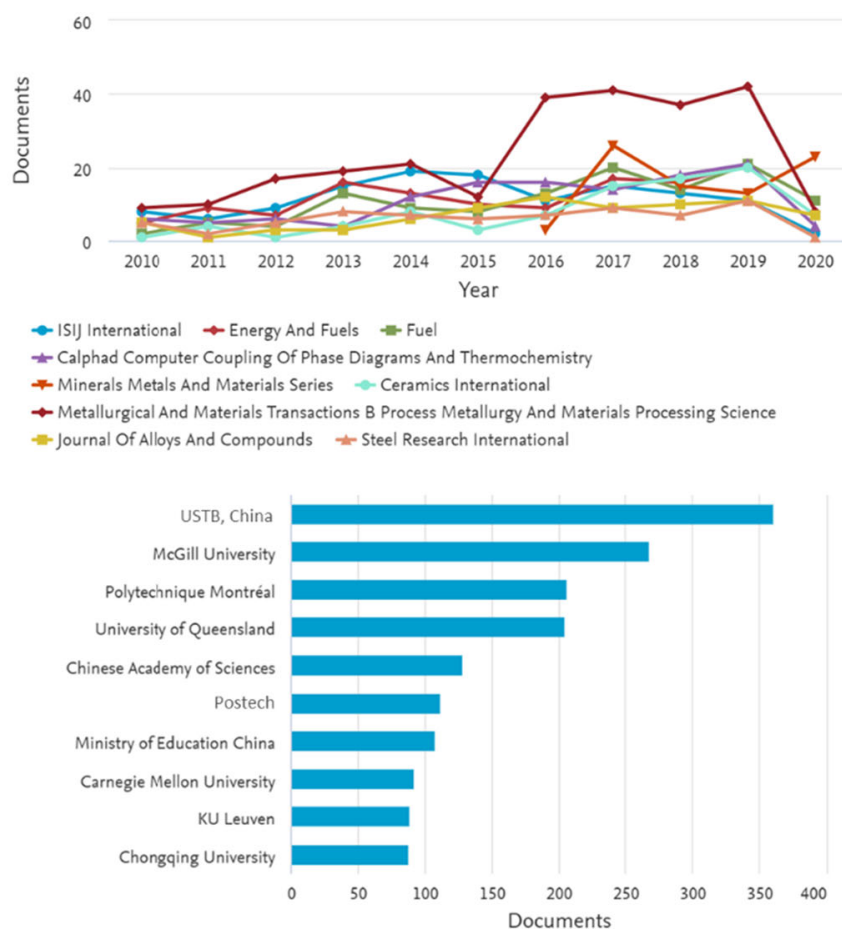

Fig. 1-Citation analysis results of the FactSage software package from SCOPUS (www.scopus.com) — search in all fields results. 
equilibrium calculations for high-purity material processes such as high-purity Si production handling $\mathrm{ppb}$ level of concentration.

The Fact and FactSage databases are the largest set of evaluated and optimized thermodynamic databases for inorganic systems in the world. All thermodynamic databases have been developed by the critical evaluation and optimization of data from literature and from new experimental results. The choice of proper thermodynamic models for each solution phase is the key factor for constructing large and comprehensive thermodynamic databases for solution phases with high predictive ability. In particular, the thermodynamic model of a solution that reflects the nature of the solution structure can readily and reasonably describe the solution mixing entropy with less and smaller temperature-dependent model parameters, providing a more accurate description of the solution Gibbs energy in wide temperature and composition range.

\section{Solution models}

General solution models applied in the CALPHAD community are described elsewhere. ${ }^{[1,6]}$ In the present study, only the Modified Quasichemical Model and Compound Energy Formalism are briefly sketched.

a. Modified Quasichemical Model One of the strengths of the FactSage thermodynamic databases is the active usage of the Modified Quasichemical Model (MQM) for complex non-ideal liquid solutions such as molten oxide, molten sulfide, molten salts, and liquid metallic solutions.

The MQM was introduced by Pelton and Blander ${ }^{[7,8]}$ in 1986 for molten slags. Compared to the classical Quasichemical Model for solid solutions readily found in thermodynamic textbook, Pelton and Blander introduced the model to liquid solutions with the following modifications: (1) assigning different coordination numbers to constituents to best describe the short-range-ordering (SRO) behavior of a liquid solution, (2) allowing the quasichemical reaction energy to vary with composition and temperature, and (3) modifying the mixing entropy function using the Ising model. The original MQM model was revised once again in 2001 by Pelton and his colleagues ${ }^{\left[{ }^{[-12]}\right.}$ to make the model more versatile: (1) the coordination number of the constituents is defined for each binary system, (2) the quasichemical reaction energy is described as function of pair fraction instead of mole fraction of constituent, and (3) both first- and second-nearest-neighbor short-range-orderings (SROs) are considered for reciprocal solution system (system consisting of two cations and two anions) with a quadruple approximation. With these revisions, the MQM can describe complex solutions more easily and accurately. The details of the MQM description can be found elsewhere. ${ }^{[9-12]}$

The MQM can also use a geometric interpolation technique to calculate equilibria in high order systems from the assessed lower order systems. ${ }^{[13,14]}$ In the prediction of the Gibbs energy of a ternary solution from the constituting binary solutions, a proper interpolation technique is necessary. The common Bragg-Williams random mixing model with Redlich-Kister-type excess parameters uses by default the Muggianu interpolation technique. ${ }^{[15]}$ However, depending on the nature of each constituting binary solution, other interpolation methods such asymmetric Toop ${ }^{[16]}$ and symmetric Kohler ${ }^{[17]}$-type interpolations can provide a more accurate prediction of the Gibbs energy in ternary solutions. ${ }^{[1]}$ In the MQM, the interpolation method for each ternary system can be readily defined depending on the nature of the binary subsystems. For example, the $\mathrm{CaO}-\mathrm{MgO}-\mathrm{FeO}$ liquid solution $^{[18]}$ is described using the Kohler interpolation method. The $\mathrm{CaO}-\mathrm{MgO}-\mathrm{SiO}_{2}{ }^{[19]}$ and $\mathrm{CaO}-\mathrm{MgO}-\mathrm{Al}_{2} \mathrm{O}_{3}$ liquid solutions ${ }^{[20]}$ can be well described using the Toop-like interpolation technique with $\mathrm{SiO}_{2}$ and $\mathrm{Al}_{2} \mathrm{O}_{3}$, respectively, as asymmetric component. The $\mathrm{CaO}-\mathrm{MgO}-\mathrm{Al}_{2} \mathrm{O}_{3}$ liquid solution was well defined without the need of additional ternary model parameters due to the choice of a proper interpolation method. The details of a geometric interpolation model description can be found elsewhere. ${ }^{[13]}$

For a liquid metallic system A-B, the MQM assumes that $\mathrm{A}$ and $\mathrm{B}$ atoms are distributed over the virtual sites of a quasi-lattice. The following pair exchange reaction is considered:

$$
(\mathrm{A}-\mathrm{A})+(\mathrm{B}-\mathrm{B})=2(\mathrm{~A}-\mathrm{B}): \Delta g_{\mathrm{AB}}
$$

where (A-B) represents a first-nearest-neighbor (FNN) pair of $\mathrm{A}$ and $\mathrm{B}$. The non-configurational Gibbs energy change for the formation of two moles of (A-B) pairs according to Reaction [1] is $\Delta g_{\mathrm{AB}}$. The Gibbs energy of the solution is given by:

$$
G^{\text {soln }}=\left(n_{\mathrm{A}} G_{\mathrm{A}}^{\mathrm{o}}+n_{\mathrm{B}} G_{\mathrm{B}}^{\mathrm{o}}\right)-T \Delta S^{\mathrm{config}}+n_{\mathrm{AB}}\left(\Delta g_{\mathrm{AB}} / 2\right)
$$

where $G_{\mathrm{A}}^{\mathrm{o}}$ and $G_{\mathrm{B}}^{\mathrm{o}}$ are the molar Gibbs energies of the pure components $\mathrm{A}$ and $\mathrm{B}, \Delta S^{\text {config }}$ the configurational entropy of mixing given by a random distribution of the (A-A), (B-B) and (A-B) pairs in the one-dimensional Ising approximation, $n_{\mathrm{A}}$ and $n_{\mathrm{B}}$ the numbers of moles of $\mathrm{A}$ and $\mathrm{B}$ atoms, and $n_{\mathrm{AB}}$ the number of moles of (A-B) pairs. $\Delta g_{\mathrm{AB}}$ is the model parameter to reproduce the Gibbs energy of the liquid phase in the binary A-B solution, which is expanded as a polynomial in terms of the pair fractions of (A-A) and (B-B). The total number of pairs in a given solution is determined depending on the coordination number of A and B. Typically, the coordination numbers of constituents are determined based on the SRO behavior of each binary solution. It should be noted that $\Delta g_{\mathrm{AB}}$ in Reaction [1] determines the number of (A-A), (B-B) and (A-B) pairs in solution, which directly influence $\Delta S^{\text {config }}$ in the Gibbs energy of the solution.

In molten oxide (slag) systems, the SRO of the second-nearest-neighbor ( $\mathrm{SNN}$ ) cations is considered in the MQM. The silicate network breaking reaction in molten slag can be equivalent to the following quasichemical reaction among SNN pairs: 


$$
(\mathrm{M}-\mathrm{M})+(\mathrm{Si}-\mathrm{Si})=2(\mathrm{M}-\mathrm{Si}): \Delta \mathrm{g}_{\mathrm{MSi}}
$$

where $(i-j)$ are pair fractions of $(i-O-j)$ pairs in molten slags. The SRO in molten silicate is taken into account through the above quasichemical reaction. The molar Gibbs energy of the reaction $\Delta g_{\mathrm{MSi}}$ is the main model parameter. A similar description can be used for molten sulfide solution where $\mathrm{S}^{2-}$ is the common anion, and other molten salt solution.

When more than two cations and two anions are mixing in a solution, both SRO of the FNN and SNN should be considered. In the MQM, the quadruplet approximation is applied. ${ }^{[11,12]}$ For example, in the case of oxy-fluoride melts, various cationic species are mixed in imaginary cationic sublattices, and anionic species of oxygen and fluorine are mixed in imaginary anionic sublattices. In order to take into account this structural information, the recently developed "Two-sublattice MQM", ${ }^{[11,12]}$ considering the short-range-ordering in both cation and anionic sublattices, is employed. Figure 2 shows the schematics of this model for the liquid $\mathrm{CaO}-\mathrm{SiO}_{2}-\mathrm{F}\left(\mathrm{CaO}-\mathrm{SiO}_{2}-\mathrm{CaF}_{2}-\mathrm{SiF}_{4}\right)$ solution. $\mathrm{Ca}^{2+}$ and $\mathrm{Si}^{4+}$ cations are considered mixed in the imaginary cationic sublattice of the melt, while $\mathrm{O}^{2-}$ and $\mathrm{F}^{-}$anions are considered mixed in the anionic sublattice. ${ }^{[21]}$ The SRO tendency of $\mathrm{Ca}^{2+}$ and $\mathrm{Si}^{4+}$ neighboring to $\mathrm{O}^{2-}$ is modeled by the binary interaction term $\Delta g_{\mathrm{CaSi} / \mathrm{OO}}$, which is optimized for the $\mathrm{CaO}-\mathrm{SiO}_{2}$ melt. Similarly, the other binary model parameters $\Delta g_{\mathrm{CaSi} / \mathrm{FF}}, \Delta g_{\mathrm{Ca} / \mathrm{OF}}$ and $\Delta g_{\mathrm{Si} / \mathrm{OF}}$ are optimized in each designated binary melt. If necessary, the reciprocal parameter $\Delta g_{\mathrm{CaSi} / \mathrm{OF}}$ can be introduced to adjust the Gibbs energy for the reciprocal melt, $\mathrm{Ca}, \mathrm{Si} / / \mathrm{O}, \mathrm{F}$.

Since the two-sublattice MQM is the extension of the previous one-sublattice model used for liquid oxide solutions, the optimized parameters of previous thermodynamic modeling of oxide melt can be easily incorporated into the new model without losing any accuracy. In this way, the FactSage liquid oxide solution database has been easily expanded to liquid oxy-fluoride solution database with the new model. ${ }^{[21]}$ The same two-sublattice MQM model has been used for oxy-sulfide solution, ${ }^{[22]}$ and molten salt solution systems. ${ }^{[23,24]}$

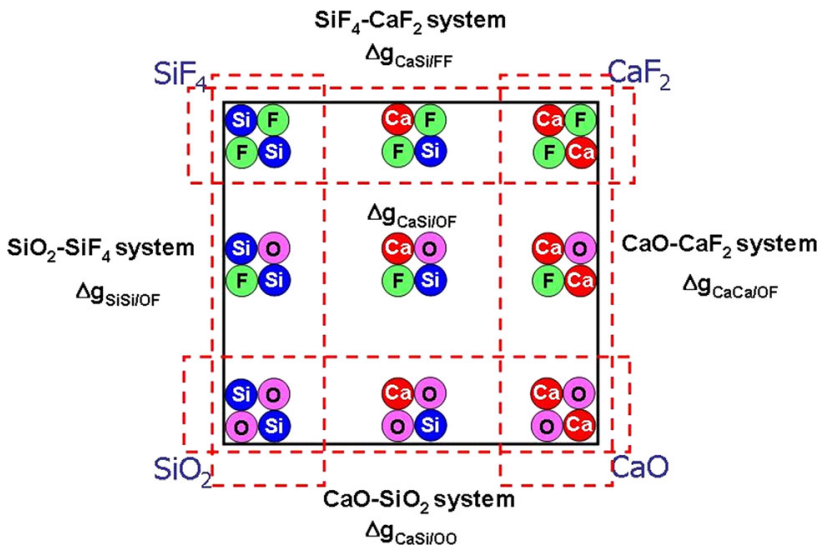

Fig. 2-Schematic diagram of new thermodynamic model for liquid $\mathrm{Ca}, \mathrm{Si} / / \mathrm{O}, \mathrm{F}$ solution $\left(\mathrm{CaO}-\mathrm{SiO}_{2}-\mathrm{CaF}_{2}\right.$ solution). Figure reprinted with permission from Ref. [21].
As part of the Gibbs energy minimization of a solution, the liquid solution structure, i.e. the pairs, can be calculated from the MQM. Figures 3(a) and (b) shows the calculated bond (pair) fractions for, respectively, the binary $\mathrm{Fe}-\mathrm{Si}$ liquid metallic solution and for the $\mathrm{CaO}-\mathrm{SiO}_{2}$ liquid oxide solution at $1600{ }^{\circ} \mathrm{C}$. The Gibbs energies of mixing of the liquid $\mathrm{Fe}-\mathrm{Si}$ solution and liquid $\mathrm{CaO}-\mathrm{SiO}_{2}$ solution at $1600{ }^{\circ} \mathrm{C}$ are about $-37 \mathrm{~kJ}$ $\mathrm{mol}^{-1}$ at 0.5 mole fraction $\mathrm{Si},{ }^{[25]}$ and $-65 \mathrm{~kJ} \mathrm{~mol}^{-1}$ at 0.33 mole fraction $\mathrm{SiO}_{2} \cdot{ }^{[26]}$ The calculated FNN bond fraction of $(\mathrm{Fe}-\mathrm{Si})$ at $x_{\mathrm{Si}}=0.5$ is 0.73 compared to 0.5 for the random mixing condition. In the case of the $\mathrm{CaO}-\mathrm{SiO}_{2}$ liquid oxide solution, the calculated SNN bond fractions of $(\mathrm{Ca}-\mathrm{Si})$ and $(\mathrm{Si}-\mathrm{Si})$, which are equivalent to broken oxygen, $\mathrm{O}^{-}$, and bridged oxygen, $\mathrm{O}^{0}$, are in good agreement with experimental melt structure data. ${ }^{[27]}$

The MQM has been successfully used to describe molten oxide (slag), molten sulfide (matte), molten salt (chloride, fluoride, etc.), liquid alloy solutions, etc. Recently, oxy-sulfide-fluoride solution, which is highly important for molten slag and flux containing both sulfide and fluoride, was well described by the MQM. Although most alloy thermodynamic databases in other commercial software use the Bragg-Williams random mixing model (assuming ideal entropy of mixing) for liquid metallic solutions, FactSage applied the MQM for liquid metallic solutions (see example for $\mathrm{Fe}-\mathrm{Al},{ }^{[28]}$ $\mathrm{Fe}-\mathrm{Si},{ }^{25]} \mathrm{Mn}-\mathrm{Al},{ }^{[29]}$ and $\left.\mathrm{Mg}-\mathrm{Si}^{[30]}\right)$. Many binary liquid metallic solutions exhibit a very negative deviation from ideal solution, which indicates short-range-ordering in the liquid solution. The MQM is certainly a better choice for such solutions compared to the Bragg-Williams random mixing model. The MQM can even absorb the modeling results carried out with the Bragg-Williams random mixing model in the MQM description, without requiring the re-optimization of all these systems (see example for $\mathrm{Mg}$-Si-Sn, ${ }^{[30]}$ $\mathrm{Fe}-\mathrm{Mn}-\mathrm{S}^{[31]}$ ). That is, the MQM also has high scalability.

b. Compound Energy Formalism The Compound Energy Formalism $(\mathrm{CEF})^{[32]}$ is widely used to describe complex and extensive solid solutions in the databases available in all thermodynamic software. The CEF is a generalized formalism describing the Gibbs energy of a solution with two or more sublattices. For the same solution, different sublattice structures can be defined by the database developer. Also, different strategies of assigning the Gibbs energy of an end-member can be set up, especially for the pseudo-end members or charged end-members that are unstable in natural condition. Therefore, the final Gibbs energy of the solid solution can be quite different depending on the developer, although the Gibbs energy description is based on the same CEF.

For example, let's assume a solid solution with the sublattice structure $(A, B)_{m}^{\mathrm{O}}[C, D]_{n}^{\mathrm{T}}$ which has $\mathrm{m}$ moles of $\mathrm{O}$ (octahedral) sites that $\mathrm{A}$ and $\mathrm{B}$ species occupy, and $\mathrm{n}$ moles of $\mathrm{T}$ (tetrahedral) sites that $\mathrm{C}$ and $\mathrm{D}$ species 


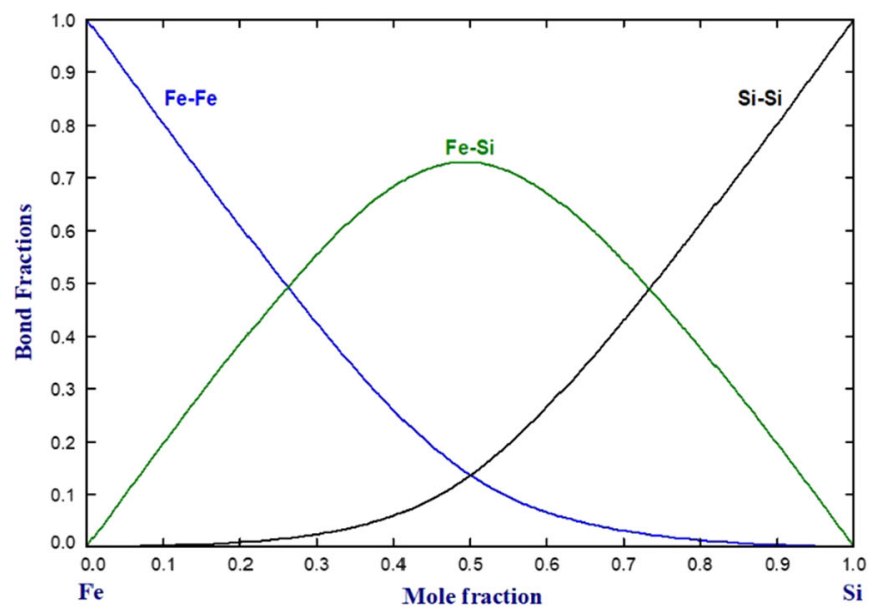

(a)

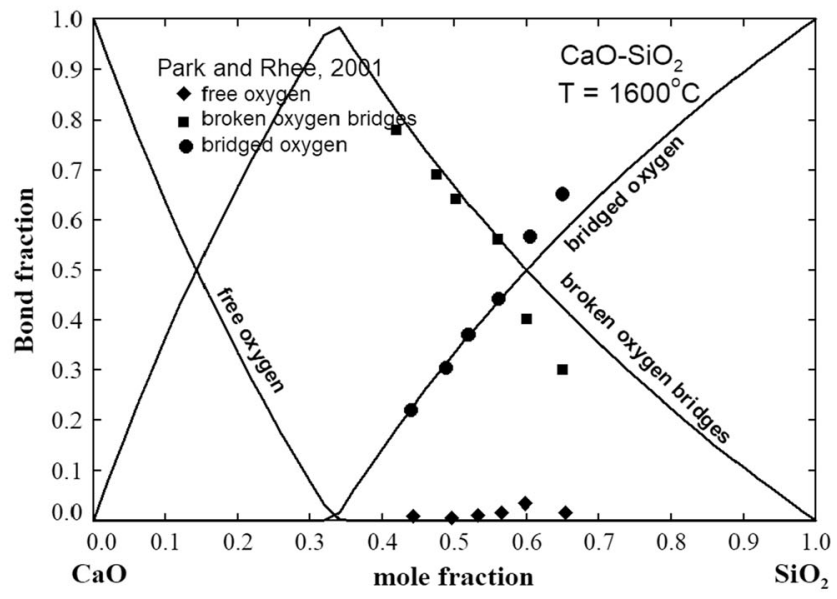

(b)

Fig. 3- Calculated bond fractions in liquid metallic solution and molten silicate from the Modified Quasichemical Model with optimized model parameters. (a) $\mathrm{Fe}-\mathrm{Si}$ solution at $1600{ }^{\circ} \mathrm{C}$, and (b) $\mathrm{CaO}-\mathrm{SiO}_{2}$ solution at $1600{ }^{\circ} \mathrm{C}$. Symbols represent the experimental data by Park and $\mathrm{Rhee}{ }^{[27]}$

occupy. A, B, C and D can be atoms, ions, and even vacancies. The Gibbs energy of the solution per mole of formula is described by the CEF as follow:

$$
\begin{aligned}
G^{\mathrm{soln}}= & \sum_{i} \sum_{j} G_{i j}^{\mathrm{o}} Y_{i}^{\mathrm{O}} Y_{j}^{\mathrm{T}}+R T\left(n_{m} \sum_{i} Y_{i}^{\mathrm{O}} \ln Y_{i}^{\mathrm{O}}\right. \\
& \left.+n_{n} \sum_{j} Y_{j}^{\mathrm{T}} \ln Y_{j}^{\mathrm{T}}\right)+G^{\mathrm{E}}
\end{aligned}
$$

where $Y_{\mathrm{i}}^{\mathrm{T}}$ and $Y_{\mathrm{j}}^{\mathrm{O}}$ represent the site fractions of constituents $i$ and $j$ on, respectively, the tetrahedral and the octahedral sublattices, $G_{i j}^{\mathrm{o}}$ is the Gibbs energy of an end member $(i)_{\mathrm{m}}^{\mathrm{O}}[j]_{\mathrm{n}}^{\mathrm{T}}$. In the CEF, the configurational entropy is described by assuming random mixing of the species in each sublattice sites. $G^{\mathrm{E}}$ is the excess Gibbs energy, which is expressed as Redlich-Kister polynomials in terms of site fractions:

$$
\begin{aligned}
G^{\mathrm{E}}= & \sum_{i} \sum_{j} \sum_{k} Y_{i}^{\mathrm{O}} Y_{j}^{\mathrm{O}} Y_{k}^{\mathrm{T} p} L_{\mathrm{ij} \mathrm{j}, \mathrm{k}}\left(Y_{i}^{\mathrm{O}}-Y_{j}^{\mathrm{O}}\right)^{\mathrm{P}} \\
& +\sum_{i} \sum_{j} \sum_{k} Y_{k}^{\mathrm{O}} Y_{i}^{\mathrm{T}} Y_{j}^{\mathrm{TP}} L_{\mathrm{k} ; \mathrm{ij}}\left(Y_{i}^{\mathrm{T}}-Y_{j}^{\mathrm{T}}\right)^{\mathrm{P}}
\end{aligned}
$$

where $L_{i j ; k}$ and $L_{k, i j}$ are the interaction energies between $i$ and $j$ on one sublattice when the other sublattice is occupied by $k$.

The main model parameters of the CEF are $G_{\mathrm{ij}}^{\mathrm{o}}$. In particular, the determination of a proper $G_{\mathrm{ij}}^{\mathrm{o}}$ value for unstable (imaginary) end-members is key in this model. A proper strategy to determine this Gibbs energy is critical to construct extensive solid solutions across multicomponent systems. If measurements of species distribution between sublattices are available, such data should also be well accounted for. This crystallographic information is important to constrain the entropy in the solid solution modeling. When vacancies and charged species are considered in the sublattices, the charge neutral condition should be taken into account by default. The Muggianu interpolation method $^{[15]}$ is embedded in the CEF by default, with no possibility to choose other symmetric or asymmetric interpolation methods.

In FactSage databases and other thermodynamic software, the CEF is used for all complex solid solutions in oxide, salt, sulfide, metal systems, etc. with a structure containing two or more sublattices.

c. Other solution models (i) One-sublattice Bragg-Williams random mixing model: When the species in solid solution are essentially mixing in only one sublattice, the CEF or the simple Bragg-Williams random mixing model (BWRM $)^{[33]}$ can be used. It should be noted that CEF and BWRM are identical in a binary system: the excess Gibbs energy parameters can be converted between models. However, the BWRM in FactSage can use various interpolation techniques for ternary and higher order systems depending on the nature of each binary subsystem, while the CEF uses by default the Muggianu interpolation technique. This flexibility in the choice of interpolation method makes the BWRM superior to the CEF for one-sublattice-structured solid solution.

(ii) Unified Interaction Parameter Formalism: The Wagner Interaction Parameter Formalism (WIPF) ${ }^{[34]}$ has been widely used in extractive metallurgy to describe the thermodynamic behavior of dilute solutes. For example, the deoxidation and desulfurization behavior in liquid steel depending on the concentration of alloying elements was well assessed using the WIPF. Unfortunately, the WIPF does not satisfy the GibbsDuhem relationship, so it is not directly implemented in CALPHAD-type computational database. Pelton and Bale $^{[35,36]}$ generalized the WIPF and proposed a revised formalism called the Unified Interaction Parameter Formalism (UIPF) that satisfies the Gibbs-Duhem relationship. The UIPF is widely used in FactSage for the liquid metal databases specialized for extractive metallurgy of steelmaking, $\mathrm{Cu}$ smelting and refining, and $\mathrm{Pb}$ and $\mathrm{Zn}$ refining. In particular, to accurately 
describe the deoxidation equilibria in liquid $\mathrm{Fe}$, an associate model was also used along with UIPF for FeLQ database in FactSage. ${ }^{[37]}$

\section{Thermodynamic databases}

FactSage has many thermodynamic databases covering a wide range of applications in material design and processing, as shown in Figure 4. Multiple databases can be selected simultaneously for complex thermodynamic calculations. The user can also develop his/her own private databases and use simultaneously with commercial databases.

In the present study, the databases widely accessed for pyrometallurgical processing are briefly reviewed below. The details of the database covering the history, elements, phases, and accuracy can be found in FactSage website (www.factsage.com).

(i) FactPS: FactPS database contains thermodynamic data of over 4900 stoichiometric phases in solid, liquid, gas and ionic state. The main sources of the data include JANAF $^{[38]}$ and Barin ${ }^{[39]}$ thermodynamic compilations. Many revised thermodynamic data are also stored after critical evaluation and optimization by the FactSage team.

(ii) FToxid: The FACT oxide database (FToxid) contains consistently assessed and critically evaluated thermodynamic data for pure oxides and oxide solid solutions formed by 23 elements (as well as for dilute solutions of $\mathrm{S}, \mathrm{SO}_{4}, \mathrm{PO}_{4}, \mathrm{H}_{2} \mathrm{O} / \mathrm{OH}, \mathrm{CO}_{3}, \mathrm{~F}, \mathrm{Cl}$ and $\mathrm{I}$ in the molten slag phase). It contains the molten slag phase, numerous extensive ceramic solid solution phases and all available stoichiometric compounds containing $\mathrm{SiO}_{2}-\mathrm{CaO}-\mathrm{MgO}-\mathrm{Al}_{2} \mathrm{O}_{3}-\mathrm{FeO}-\mathrm{Fe}_{2} \mathrm{O}_{3}-\mathrm{MnO}-\mathrm{TiO}_{2}-\mathrm{Ti}_{2} \mathrm{O}_{3}-$ $\mathrm{CrO}-\mathrm{Cr}_{2} \mathrm{O}_{3}-\mathrm{ZrO}_{2}-\mathrm{NiO}-\mathrm{CoO}-\mathrm{Na}_{2} \mathrm{O}-\mathrm{K}_{2} \mathrm{O}-\mathrm{Li}_{2} \mathrm{O}-\mathrm{B}_{2} \mathrm{O}_{3}-$ $\mathrm{P}_{2} \mathrm{O}_{5}-\mathrm{Cu}_{2} \mathrm{O}-\mathrm{As}_{2} \mathrm{O}_{3}-\mathrm{GeO}_{2}-\mathrm{PbO}-\mathrm{SnO}-\mathrm{ZnO}$. The core $\mathrm{Al}_{2} \mathrm{O}_{3}-\mathrm{CaO}-\mathrm{FeO}-\mathrm{Fe}_{2} \mathrm{O}_{3}-\mathrm{MgO}-\mathrm{MnO}-\mathrm{SiO}_{2}$ system has been fully optimized from $25{ }^{\circ} \mathrm{C}$ to above liquidus temperatures at all compositions and oxygen partial pressures. Components like $\mathrm{B}_{2} \mathrm{O}_{3}, \mathrm{~K}_{2} \mathrm{O}, \mathrm{Na}_{2} \mathrm{O}, \mathrm{Li}_{2} \mathrm{O}$, $\mathrm{CoO}, \mathrm{CrO}, \mathrm{Cr}_{2} \mathrm{O}_{3}, \mathrm{P}_{2} \mathrm{O}_{5}, \mathrm{Cu}_{2} \mathrm{O}, \mathrm{NiO}, \mathrm{PbO}, \mathrm{SnO}, \mathrm{TiO}_{2}$, $\mathrm{Ti}_{2} \mathrm{O}_{3}, \mathrm{ZnO}$, and $\mathrm{ZrO}_{2}$ were added to this core seven-component system and the relevant subsystems were optimized over composition ranges important for industrial applications. The molten slag phase is

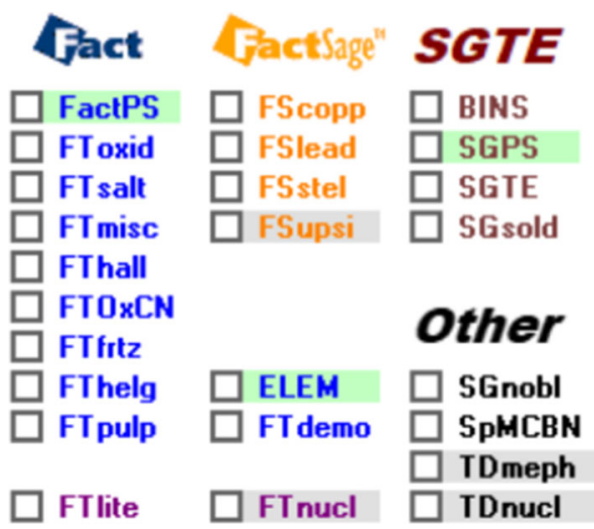

Fig. 4-Available commercial thermodynamic databases in FactSage software package. described using the MQM. The $\mathrm{S}$ and $\mathrm{F}$ content in molten oxide slag is extended up to pure sulfide and fluoride using the new two-sublattice MQM. The dilute solubilities of gaseous species such as $\mathrm{SO}_{4}, \mathrm{H}_{2} \mathrm{O}, \mathrm{OH}, \mathrm{C}$, $\mathrm{CO}_{3}, \mathrm{CN}, \mathrm{Cl}$, and $\mathrm{I}$ are also modeled using the Blander-Reddy Model. ${ }^{[40-43]}$ The extensive solid solutions such as spinel, olivine, melilite, pyroxenes, monoxide, perovskite, wollastonite, etc. are modeled in the framework of the $\mathrm{CEF}$, taking into account the crystal structure of each solution. Over 80 solid oxide solutions are available in FToxid database.

In particular, the molten slag phase is a key phase in many pyrometallurgical processes. For the description of mineral ores, refractories, inclusions, and other solid slags, solid solutions and stoichiometric compounds are important.

(iii) FTsalt: The FTsalt databases contain data for pure salts and salt solutions of 27 main cations $\left(\mathrm{Li}^{+}\right.$, $\mathrm{Na}^{+}, \mathrm{K}^{+}, \mathrm{Rb}^{+}, \mathrm{Cs}^{+}, \mathrm{Mg}^{2+}, \mathrm{Ca}^{2+}, \mathrm{Sr}^{2+}, \mathrm{Ba}^{2+}, \mathrm{Mn}^{2+}$, $\mathrm{Al}^{3+}, \mathrm{Fe}^{2+}, \mathrm{Fe}^{3+}, \mathrm{Co}^{2+}, \mathrm{Ni}^{2+}, \mathrm{Zn}^{2+}, \mathrm{Pb}^{2+}, \mathrm{La}^{3+}$, $\mathrm{Ce}^{3+}, \mathrm{Th}^{4+}, \mathrm{U}^{3+}, \mathrm{U}^{4+}, \mathrm{Pu}^{3+}, \mathrm{Pu}^{4+}, \mathrm{Cr}^{2+}, \mathrm{Cr}^{3+}$, $\left.\mathrm{Mo}^{5+}\right)$ and 9 main anions $\left(\mathrm{F}^{-}, \mathrm{Cl}^{-}, \mathrm{Br}^{-}, \mathrm{I}^{-}, \mathrm{NO}_{3}{ }^{-}\right.$, $\left.\mathrm{NO}_{2}{ }^{-}, \mathrm{OH}^{-}, \mathrm{CO}_{3}{ }^{2-}, \mathrm{SO}_{4}{ }^{2-}\right)$. Dilute amounts of $\mathrm{O}^{2-}$ and $\mathrm{OH}^{-}$are also allowed in the molten salt phase. In particular, a wide range of $\mathrm{F}$ systems and $\mathrm{Cl}$ systems are covered. Systems made with certain combination of $\mathrm{F}^{-}$ and $\mathrm{Cl}^{-}$with $\mathrm{Br}^{-}, \mathrm{I}^{-}, \mathrm{NO}_{3}^{-}, \mathrm{OH}^{-}, \mathrm{CO}_{3}{ }^{2-}$, and $\mathrm{SO}_{4}{ }^{2-}$ are available. The database can be utilized for various molten salt-based applications such as refining fluxes for liquid $\mathrm{Al}$ and $\mathrm{Mg}$ alloy production, electrochemical processes, low-temperature energy storage materials using phase transition, incineration/combustion and various recycling processes. The FTsalt database can also be used for alloy corrosion study in chlorine and fluorine environments. Recent molten salt nuclear reactor is also covered with a specialized liquid solution of $\mathrm{Li}^{+}, \mathrm{Th}^{4+}, \mathrm{U}^{3+}, \mathrm{U}^{4+}, \mathrm{Pu}^{3+}, \mathrm{Pu}^{4+}, \mathrm{Cr}^{2+}, \mathrm{Cr}^{3+}, \mathrm{Ni}^{2+}$, $\mathrm{Mo}^{5+} / / \mathrm{F}$.

(iv) FTmisc: The FTmisc database contains the liquid sulfide (matte) solution. This is the key solution for non-ferrous smelting processes using sulfide minerals. For smelting processes, the liquid matte solution for the system $\mathrm{S}-\mathrm{Cu}-\mathrm{Fe}-\mathrm{Ni}-\mathrm{Co}-\mathrm{Pb}-\mathrm{Zn}-\mathrm{As}$, described by the MQM, is available. There are also complete descriptions of solid and liquid solutions for the Fe-Ni-Cr-Co-Cu-S system from pure metal to pure sulfur. This can be utilized for the metallization of mattes by cooling process. FTmisc also contains many dilute liquid metal solutions such as FeLQ, CuLQ, PbLQ, SbLQ, SeLQ, SnLQ, TeLQ, and ZnLQ, described by the UIPF, for extractive metallurgical processes.

(v) FThall: This database was developed for the Hall-Heroult aluminum electrochemical reduction process. It allows the thermodynamic and phase equilibrium calculations involving liquid metal-cryolitic bath- $\mathrm{Al}_{2} \mathrm{O}_{3}$-based oxides in alumina reduction electrolysis cells, and for molten aluminum treatment with fluoride fluxes. The FThall database is a self-contained database for the Al-Mg-Na-Li-Ca-F-O-C system. No extra phases from other databases are needed for this 8-component system. 
(vi) FThelg: The FThelg solution database contains infinite dilution properties for over 1400 aqueous solute species taken from the GEOPIG-SUPCRT Helgeson public database. These incorporate the Helgeson equation of state for temperatures up to $350{ }^{\circ} \mathrm{C}$ and pressures up to 165 bar. Three aqueous solutions covering up to 0.5 molarity described by an extended Debye-Huckel (Davies) equation is available. The database can be used for corrosion study of alloys at aqueous or steam environment, and the purification process of brine for $\mathrm{LiCO}_{3}$ or $\mathrm{LiOH}$ production.

(vii) FTOxCN, FTfrtz, FTpulp: FTOxCN is metal-oxide-carbide-nitride database covering the Al-(Si-Ca-Mg-Fe-Na)-C-O-N-S system at very high temperatures. This database was originally developed for the high temperature carbothermic reduction process of alumina to produce liquid aluminum. The FTfrtz databases contain data for pure salts and salt solutions based on the family of ammonium nitrate $\left(\mathrm{NH}_{4} \mathrm{NO}_{3}\right)$, mono-ammonium di-hydrogen phosphate $\left(\mathrm{NH}_{4} \mathrm{H}_{2} \mathrm{PO}_{4}\right)$, ammonium chloride $\left(\mathrm{NH}_{4} \mathrm{Cl}\right)$, and ammonium sulfate $\left(\left(\mathrm{NH}_{4}\right)_{2} \mathrm{SO}_{4}\right)$ fertilizers with additions of their corresponding potassium salts (and in some cases sodium salts). The model covers the addition of roughly up to 50 wt pct of water. It can calculate the phase transitions down to $-25{ }^{\circ} \mathrm{C}$ for fertilizer production process. FTpulp is the specialized database for the thermodynamic and phase equilibrium calculations involving molten and solid alkali salts related to the combustion of black liquor in the recovery boiler of pulp and paper mills. It is also related to combustion and corrosion-related processes in biomass combustion. The FTpulp database covers the Na-K-S-C-O-Cl-H system.

(viii) Metallic databases: FTlite (Al and $\mathrm{Mg}$ alloys), FSstel (Steel), FScopp ( $\mathrm{Cu}$ alloy), FSlead (Pb alloy), FSupsi (ultra high-purity $\mathrm{Si}$ ) are alloy databases. Using these database, new alloys and specific process condition for heat treatment can be calculated. The alloy databases can also be used in combination with other databases listed above to calculate multiphase equilibria for applications in oxidation, corrosion, liquid alloy processing, etc.

(ix) SpMCBN: This is a newly added database for refractory metals and hard coating materials containing metal-carbide-boride-nitride. It covers solid and liquid phases for the system $\mathrm{B}, \mathrm{C}, \mathrm{N}$, Si with $\mathrm{Al}, \mathrm{Ca}, \mathrm{Co}, \mathrm{Cr}$, Fe, Hf, Mg, Mn, Mo, Nb, Ni, Re, Sc, Ta, Tc, Ti, V, W, $\mathrm{Y}, \mathrm{Zr}$. It also contains some of the so-called MAX and MAXEN phases.

(x) SGTE database: The SGTE metallic database is a large metallic database covering a wide range of metal systems, but is not well tuned for specific alloy applications like steel and light alloys. SGsold and SGnobl are alloy databases for solder metals and noble metals, respectively.

(xi) Nuclear database: FTnucl, TDnucl, and TDmeph databases are developed for nuclear fuel and nuclear reaction application. Their coverages are different (see the details in www.factsage.com).

\section{Physical property models and databases}

In pyrometallurgical processes, the physical property of molten slag and molten salts are important. In FactSage, the viscosity database ${ }^{[44-48]}$ for multicomponent molten slags containing $\mathrm{SiO}_{2}-\mathrm{CaO}-\mathrm{MgO}-\mathrm{Li}_{2} \mathrm{O}-$ $\mathrm{Na}_{2} \mathrm{O}-\mathrm{K}_{2} \mathrm{O}-\mathrm{Al}_{2} \mathrm{O}_{3}-\mathrm{FeO}-\mathrm{Fe}_{2} \mathrm{O}_{3}-\mathrm{MnO}-\mathrm{NiO}-\mathrm{CoO}-\mathrm{PbO}-\mathrm{ZnO}-$ $\mathrm{TiO}_{2}-\mathrm{Ti}_{2} \mathrm{O}_{3}-\mathrm{B}_{2} \mathrm{O}_{3}-\mathrm{CaF}_{2}$ is available. This database is developed based on a structural viscosity model considering the structure change in molten slag. As presented in Figure 3, the MQM can accurately calculate the bond structure of molten slag. This 1-D (dimension) bond information can be utilized to calculate the 3-D structure of the molten slag, such as the silicate structural unit $Q^{n}$, where $n$ represents the number of bridged oxygen in the silica tetrahedron. Briefly speaking, the structural viscosity model is an Arrhenius-type viscosity model containing the viscosity activation energy for a complex silicate structure, which is calculated from bond fractions by the MQM. With a limited number of model parameters, the model can accurately predict the viscosity of multicomponent oxide slags and oxy-fluoride slags. The model is even further developed to calculate the viscosity of glass.

Based on the molar volume of each silicate structural unit $Q^{n}$ with a basic oxide cation, the molar volume (density) of slag was also modeled for the $\mathrm{SiO}_{2}-\mathrm{CaO}-$ $\mathrm{MgO}-\mathrm{Li}_{2} \mathrm{O}-\mathrm{Na}_{2} \mathrm{O}-\mathrm{K}_{2} \mathrm{O}-\mathrm{Al}_{2} \mathrm{O}_{3}-\mathrm{FeO}-\mathrm{Fe}_{2} \mathrm{O}_{3}-\mathrm{MnO}-\mathrm{PbO}$ slag systems. ${ }^{[4-51]}$ The density of molten salt of the $\left(\mathrm{Li}^{+}, \mathrm{Na}^{+}, \mathrm{K}^{+}, \mathrm{Mg}^{2+}, \mathrm{Ca}^{2+} / / \mathrm{Cl}^{-}, \mathrm{F}^{-}\right)$system is also available in the FTsalt database. ${ }^{[52]}$ The molar volume for liquid and solid phases in the Al-Mg-Zn-Fe-Mn system is modeled and stored in the FTlite database. ${ }^{[53]}$

The slag structural information from the MQM was even used for the development of an electrical conductivity model for slag. The electrical conductivity model is based on the Nernst-Einstein relationship, and the diffusivity was described as function of bond fraction. The model can successfully explain the conductivity for the $\mathrm{CaO}-\mathrm{MgO}-\mathrm{MnO}-\mathrm{PbO}-\mathrm{Al}_{2} \mathrm{O}_{3}-\mathrm{SiO}_{2}$ slag and for melts with limited amount of $\mathrm{FeO}$ and $\mathrm{Fe}_{2} \mathrm{O}_{3}$. ${ }^{[54,55]}$

The molar volume database and electrical conductivity database for molten slags are not available yet in the FactSage software package.

\section{Industrial Consortia for Database Development}

FactSage databases have been developed by longterm industrial collaborations and by following the needs of the industry, as illustrated in Figure 5. The first industrial consortium project was 'FactSage Industrial Consortium Project' sponsored by 15 industrial members and the Natural Science and Engineering Research Council (NSERC) of Canada. For this 3-year consortium project, the previous single FACT database mainly for process metallurgy was divided into more specific database and extensively upgraded. Many new metallic databases were also developed during this consortium project. The current FactSage database structure in Figure 4 was more or less obtained at the end of this project. 


\begin{tabular}{l}
\hline "FactSage Industrial Consortium Project" (2001-2003) \\
led by Prof. Arthur Pelton \\
(Ecole Polytechnique de Montreal) \\
with Noranda, Inco, Rio Tinto - Iron \& Titanium, \\
Teck Cominco, Alcoa, DuPont, Shell, Corning, Schott \\
AG, Norsk Hydro, Saint-Gobain, Mintek, Pechiney, \\
SINTEF, I.I.S. Materials, and NSERC
\end{tabular}

"Aluminum Consortium Project" (2005 present) led by Prof. Patrice Chartrand

(Ecole Polytechnique de Montreal)

with Alcoa, Constellium, Hydro Aluminium and Rio

Tinto Aluminum and NSERC

"Steelmaking Consortium Project" (2009 Present)

led by Prof. In-Ho Jung

(Seoul National University)

with Doosan Heavy Ind. \& Con., JFE Steel,

Nippon Steel, Nucor Steel, Hyundai Steel, Posco,

RHI-Magnesita, Rio Tinto, SeAH Besteel,

Tata Steel Europe, and Voestalpine

“Glasses Consortium Project" (2005 Present)

led by Dr. Sergei Decterov

(Ecole Polytechnique de Montreal)

with Schott AG, Corning, and Saint-Gobain

"Non-ferrous and Coals Consortium Projects"

led by Profs. Evgueni Jak and Peter Hayes

(Univ. Queensland)

With many non-ferrous and ferrous companies

Fig. 5-Major industrial consortia for the development of FactSage thermodynamic databases.

From 2005, specific industrial consortia were created and up-running for more than 10 years in order to develop the databases for the specific industrial sector's needs. The aluminum consortium project led by Prof. P. Chartrand has improved the FTsalt and FTlite databases. The glass consortium project led by Dr. S. Decterov has upgraded the FToxid database. The steelmaking consortium project led by Prof. I.-H. Jung has contributed to the expansion of the FToxid, FSstel, and FTmisc databases. Although not directly connected to the FactSage database development, the consortium projects for non-ferrous and coal industry created by Profs. E. Jak and P. Hayes led to the development of private thermodynamic databases for the non-ferrous smelting processes and coal combustion processes, and the published results have been used to improve the FToxid database.

An overview of the database development in the FactSage Steelmaking consortium project is presented in Figure 6. In the Steelmaking consortium project, thermodynamic databases are developed based on available literature data. When the phase diagram data in literature are insufficient, new phase diagram experiments are carried out. In 2009 to 2014, $\mathrm{P}_{2} \mathrm{O}_{5}$ was incorporated into the oxide database in order to satisfy the industrial needs to develop better technology of de-phosphorization of liquid steel. In addition, the liquid oxide solution was expanded by including $\mathrm{F}$, $\mathrm{Na}_{2} \mathrm{O}, \mathrm{K}_{2} \mathrm{O}$, and $\mathrm{Li}_{2} \mathrm{O}$ to provide an accurate database for mold flux and special refining flux. This database was used by industrial members to develop new mold flux and refining slags for special steels. In the period

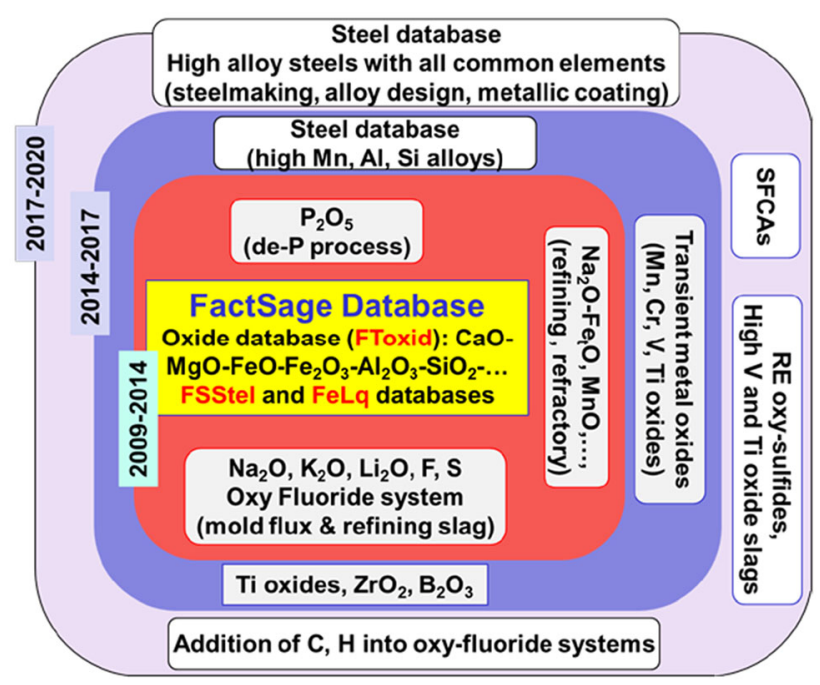

Fig. 6-FactSage Steelmaking Consortium Project (http://in-hogroup.snu.ac.kr): overview of thermodynamic database development.

2014 to 2017, the oxide database was expanded to higher concentration of $\mathrm{Ti}, \mathrm{Mn}, \mathrm{Cr}, \mathrm{V}$ oxide. $\mathrm{ZrO}_{2}$-related systems, especially important for refractory applications in the steelmaking process, were modeled. A new steel database (solid and liquid phases) for the system Fe-Mn-Al-Si-C-with minor elements was also developed to provide a good guidance for advanced high strength steel development. The MQM was applied for the liquid steel for the first time. In the period 2017 to 2020, the FToxid database has been continuously expanded toward high $\mathrm{Ti}, \mathrm{Mn}, \mathrm{Cr}, \mathrm{V}$, and $\mathrm{Zr}$ oxide region. 
Modeling of rare earth oxides in the $\mathrm{CaO}-\mathrm{MgO}-\mathrm{Al}_{2} \mathrm{O}_{3}$ $\mathrm{SiO}_{2}$ system is in progress. A new database for the iron ore sintering process covering the $\mathrm{FeO}-\mathrm{Fe}_{2} \mathrm{O}_{3}-\mathrm{CaO}$ $\mathrm{MgO}-\mathrm{Al}_{2} \mathrm{O}_{3}-\mathrm{SiO}_{2}$ system with SFCA and SFCA-I phases has been developed. The new steel database covering the entire steel chemistry has been developed. This database especially includes good descriptions of the FCC and BCC ordered and disordered phases, the conventional $\mathrm{Zn}$ and new Al-Mg-Si metallic coating systems, and the peritectic grade steels containing high $\mathrm{Mn}, \mathrm{Si}$, and $\mathrm{Al}$ concentrations. The liquid steel is described with the MQM. After the priority period of the database usage by the consortium members, the consortium databases have been gradually released for FactSage users. For example, $\mathrm{P}_{2} \mathrm{O}_{5}$ containing systems were released in FToxid 7.0 version, oxy-fluoride systems in FToxid 7.1, $\mathrm{K}_{2} \mathrm{O}$ containing systems in FToxid 7.3, and $\mathrm{Li}_{2} \mathrm{O}$ containing systems in FToxid 8.0. The newly developed steel database is also released as FSstel 8.0 database. The viscosity database for oxy-fluoride systems, $\mathrm{Fe}$ oxide rich systems, and $\mathrm{Li}_{2} \mathrm{O}$ containing systems were improved, and all available in FactSage 8.0.

\section{APPLICATIONS}

As seen in Figure 1, FactSage has been widely used in the material processing field. There have been several good collections of application examples. ${ }^{[3,4,56-59]}$ In the present study, many examples covering typical steel production process are calculated using the most recent FactSage 8.0 databases and steelmaking consortium databases.

\section{A. Iron Ore Sintering Process}

Sinter ore is the main iron burden of the ironmaking process for many steel producers. A blend of fine ores is mixed with limestone flux and coke breeze and heated by the combustion of coke breeze to produce a sinter ore. The sinter microstructure is an important factor determining the mechanical strength and reducibility of the sinter in the ironmaking process. However, due to the depletion in high grade iron ore, the level of impurities increases which results in difficulty in controlling the sinter microstructure. The sintering process involves both temperature and $\mathrm{P}\left(\mathrm{O}_{2}\right)$ change, and the main chemistry of the sinter is $\mathrm{FeO}-\mathrm{Fe}_{2} \mathrm{O}_{3}-\mathrm{CaO}$ $\mathrm{MgO}-\mathrm{Al}_{2} \mathrm{O}_{3}-\mathrm{SiO}_{2}$, excluding water and coke breeze. During the rapid heating process by the combustion of coke breeze with air, the temperature can increase above $1300{ }^{\circ} \mathrm{C}$ with $\mathrm{P}\left(\mathrm{O}_{2}\right)$ down to $10^{-4}$ or $10^{-5} \mathrm{~atm}$. Then, the sinter is steadily cooled down to room temperature by air. Therefore, the thermodynamic and kinetic understanding of the reduction and oxidation process of the green mix with temperature is important. Recently, quaternary silicoferrite of calcium and aluminum (SFCA) phase was found in the $\mathrm{Fe}_{2} \mathrm{O}_{3}-\mathrm{CaO}-\mathrm{Al}_{2} \mathrm{O}_{3}-\mathrm{SiO}_{2}$ system. The SFCA phase is important because this phase can form during the heating and cooling process of sinter ore containing higher $\mathrm{Al}_{2} \mathrm{O}_{3}$ content.
Figure 7 shows thermodynamic calculations of a sinter ore $\left(80.5 \mathrm{Fe}_{2} \mathrm{O}_{3}+6.2 \mathrm{SiO}_{2}+12.3 \mathrm{CaO}+1.0\right.$ $\mathrm{Al}_{2} \mathrm{O}_{3}$, in wt pct) with temperature and oxygen partial pressure using the new steelmaking consortium SFCA database. The variation of phase amount depending on temperature is calculated in air (Figure 7(a)) and at $\mathrm{P}\left(\mathrm{O}_{2}\right)=10^{-3}$ atm (Figure 7(b)). Both results are similar until $1150{ }^{\circ} \mathrm{C}$. Thermodynamically, SFCA can form in solid state, but kinetically, this hardly happens during such short sintering process. The reduction of hematite to magnetite is calculated at $\mathrm{P}\left(\mathrm{O}_{2}\right)=10^{-3}$ atm from $1150{ }^{\circ} \mathrm{C}$. The melting occurs at $1210{ }^{\circ} \mathrm{C}$ to $1220{ }^{\circ} \mathrm{C}$ in both cases. The $\mathrm{P}\left(\mathrm{O}_{2}\right)$-T phase diagram of the sinter ore is calculated in Figure 7(c). Two arbitrary trajectories of heating and cooling are drawn in the figure. In general, the higher amount of coke breeze, the higher temperature, and the lower $\mathrm{P}\left(\mathrm{O}_{2}\right)$ can be expected in sintering process. During the cooling process, hematite and SFCA can crystallize from the liquid phase. These types of thermodynamic calculations can give a general idea on how the process parameters, impurity, and flux composition can change the final sinter mineralogy and microstructure.

\section{B. Alkali Circulation and Corrosion of Refractory in Blast Furnace}

In the blast furnace, one of the important challenges is to control the buildup of alkali $\left(\mathrm{K}_{2} \mathrm{O}\right.$ and $\left.\mathrm{Na}_{2} \mathrm{O}\right)$. Alkali are naturally present in the raw materials. Alkali oxide can be reduced by coke and evaporates to the gas phase in the hot zone (lower part) of the blast furnace. The gaseous alkali species condensate back to alkali oxide in the cold zone (middle part) of the blast furnace. As a result, alkali accumulates in the blast furnace, which is called the alkali circulation phenomenon. Alkali circulation and accumulation cause many problems: (i) it condenses on the surface of lump, sinter, and pellets, causing a decrease in mechanical strength, fracture, and deterioration in gas permeability, and (ii) it (in particular, $\mathrm{K}(\mathrm{g})$ ) can penetrate the refractory bricks through voids and brick joints, and produce new solid or liquid phase by reacting with mullite-type refractory, which is responsible of the degradation of the refractory lining.

The formation of K-rich gas phase in the bosh zone is calculated in Figure 8. A typical bosh slag containing 2 wt pct $\mathrm{K}_{2} \mathrm{O}$ is assumed, and reacted with carbon at 1600 ${ }^{\circ} \mathrm{C}$. According to the calculation results, a K-rich gas phase can be formed. The K-rich gas is saved and cooled down to simulate the K circulation (Figure 9). According to the equilibrium calculation result, liquid slag and carbon condense from the gas phase with decreasing temperature, and the slag is mainly composed of $\mathrm{K}_{2} \mathrm{O}$ and $\mathrm{SiO}_{2}$. The ratio of $\mathrm{K}_{2} \mathrm{O} / \mathrm{SiO}_{2}$ increases with decreasing temperature.

As shown in the calculations, when the K-rich gas condenses on the sinter ore or pellets, it produces $\mathrm{K}_{2} \mathrm{O}-\mathrm{SiO}_{2}$ slag and reduce the melting temperature of sinter and pellets, and eventually reduce the permeability in the blast furnace. Due to similar reason, $\mathrm{K}_{2} \mathrm{O}$-rich 


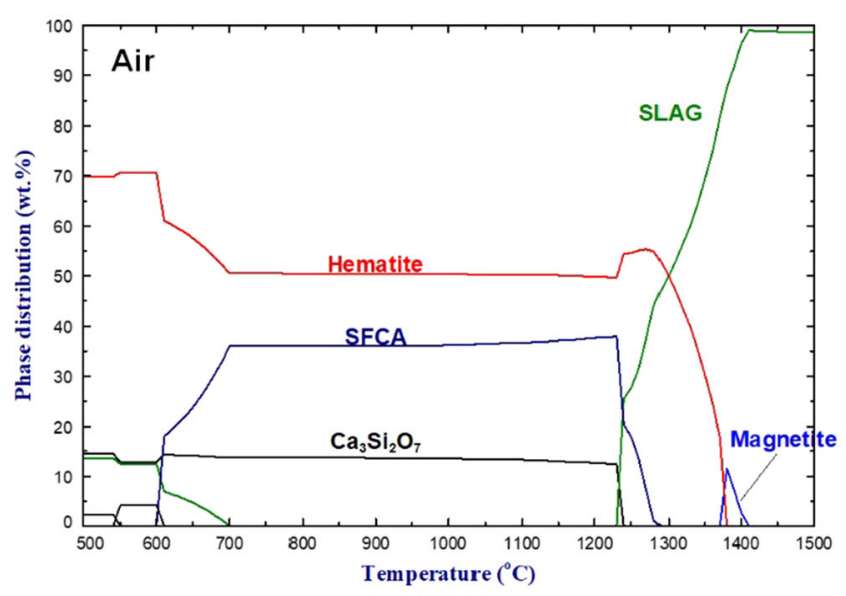

(a)

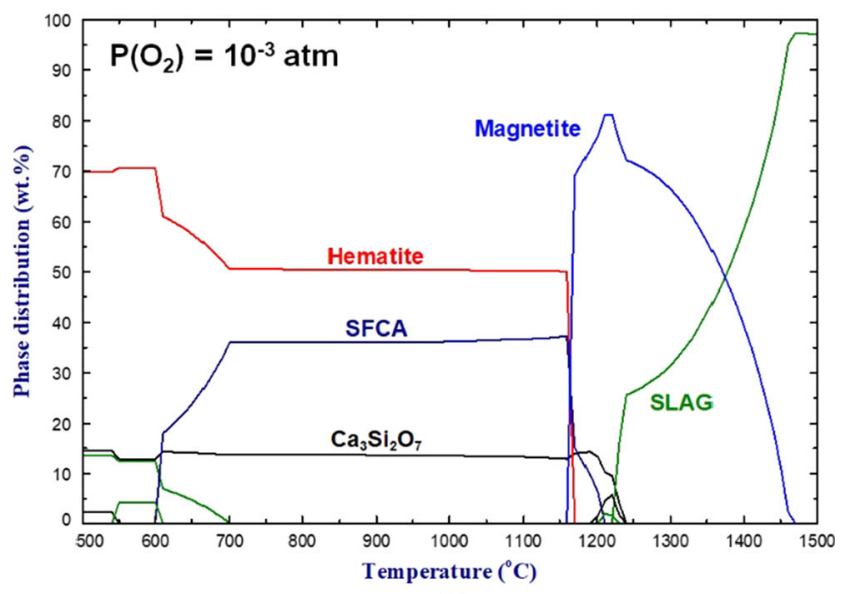

(b)

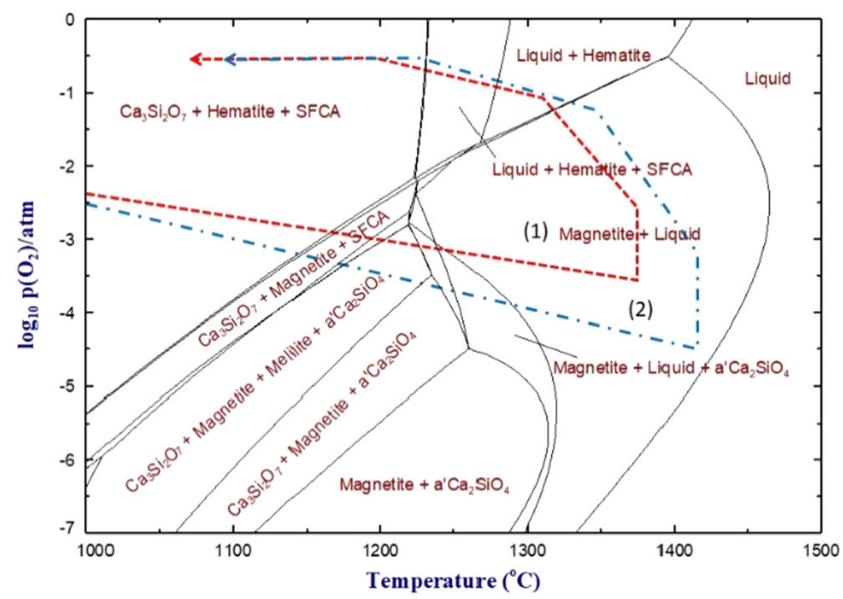

(c)

Fig. 7-Application of SFCA database for iron ore sintering process. Sinter composition is, in wt pct, 80.5 $\mathrm{Fe}_{2} \mathrm{O}_{3}+6.2 \mathrm{SiO}_{2}+12.3 \mathrm{CaO}+1.0 \mathrm{Al}_{2} \mathrm{O}_{3}$. Equilibrium phase evolution with temperature $(a)$ at air, and $(b) \mathrm{P}\left(\mathrm{O}_{2}\right)=10^{-3}$ atm. $(c) \mathrm{P}\left(\mathrm{O}_{2}\right)-\mathrm{T}$ diagram.

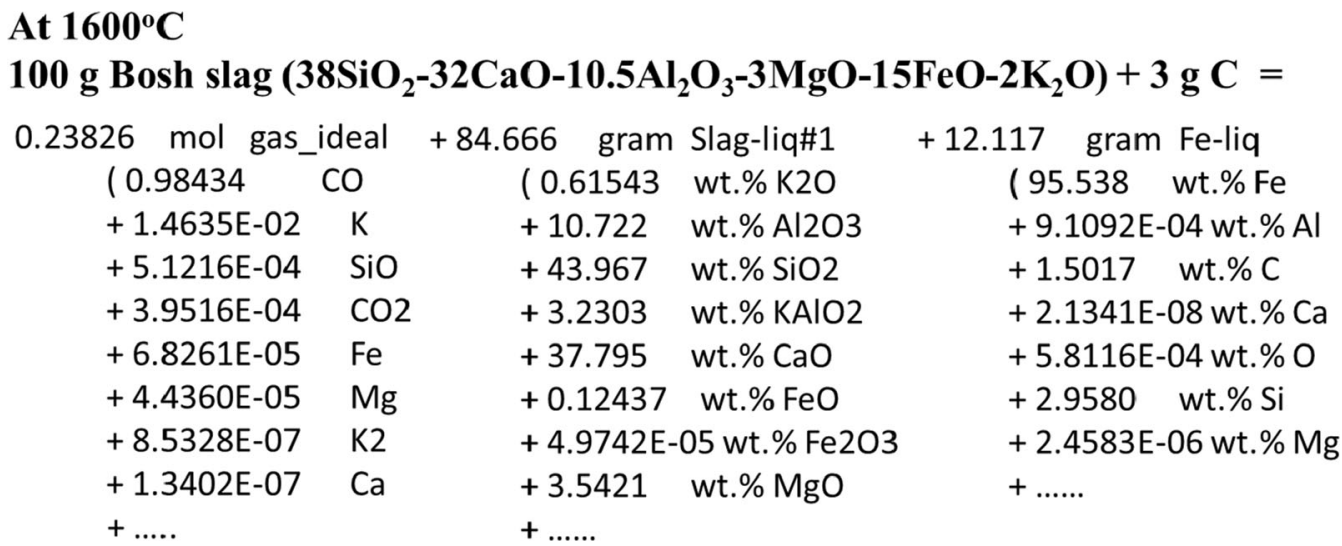

Fig. 8 - Calculation of the $\mathrm{K}$ vaporization in the bosh zone of blast furnace.

silicate melt can condense on mullite refractory causing scaffold formation. When it forms kaliophilite $\left(\mathrm{KAlSiO}_{4}\right)$ by reacting with mullite refractory, it can even induce spalling of refractory due to volume expansion.

\section{BOF Process: De-phosphorization of Hot Metal}

The main purpose of the BOF process is the decarburization of the hot metal by blowing oxygen gas. At the same time, de-phosphorization occurs due to the high oxygen potential condition. The final BOF slag 


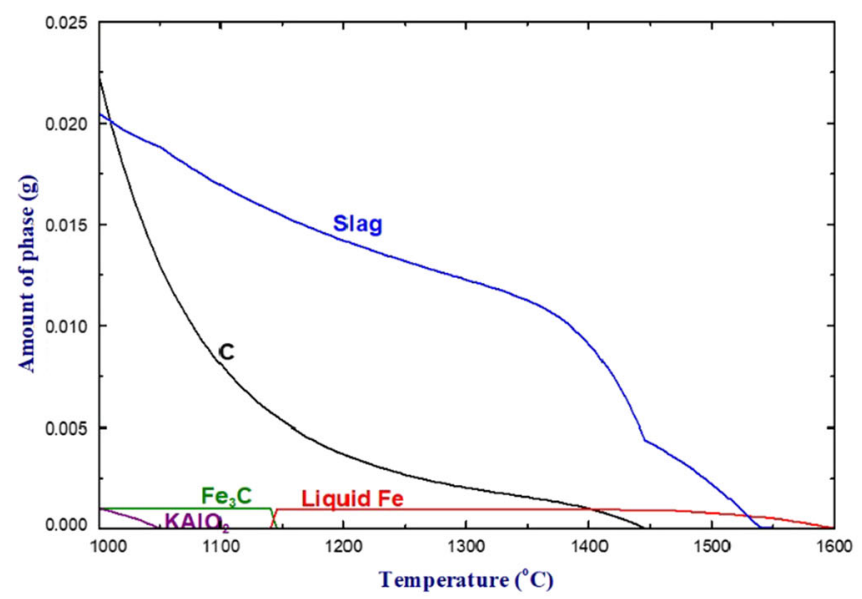

(a)

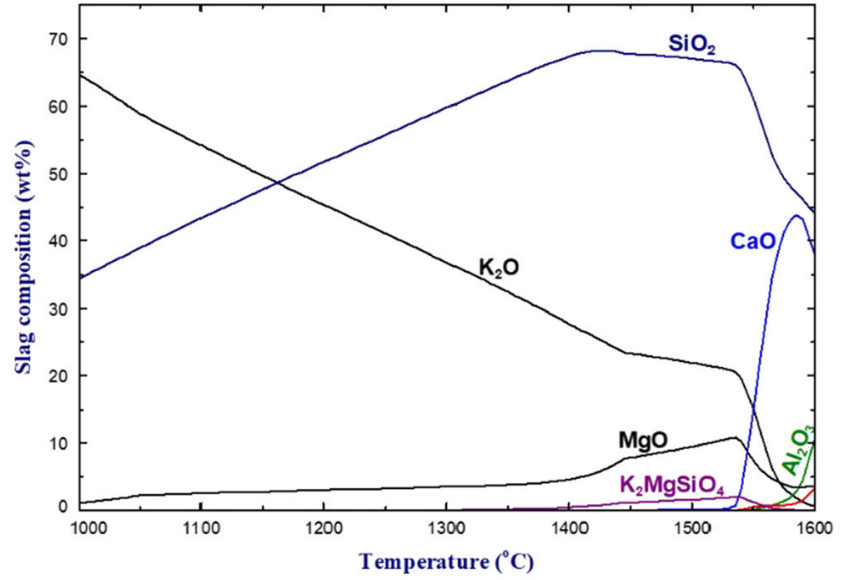

(b)

Fig. 9-Condensation of the K-rich gas phase produced in the bosh zone (see Fig. 8) in the cold zone in blast furnace: (a) amount of liquid slag and solid phases condensated from the gas phase with decreasing temperature, and $(b)$ variation of condensated slag composition with temperature.

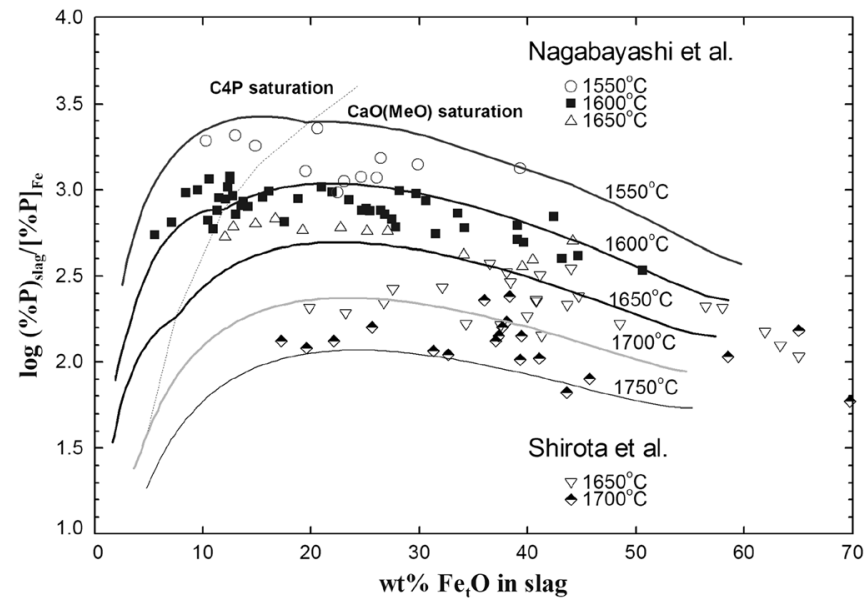

(a)

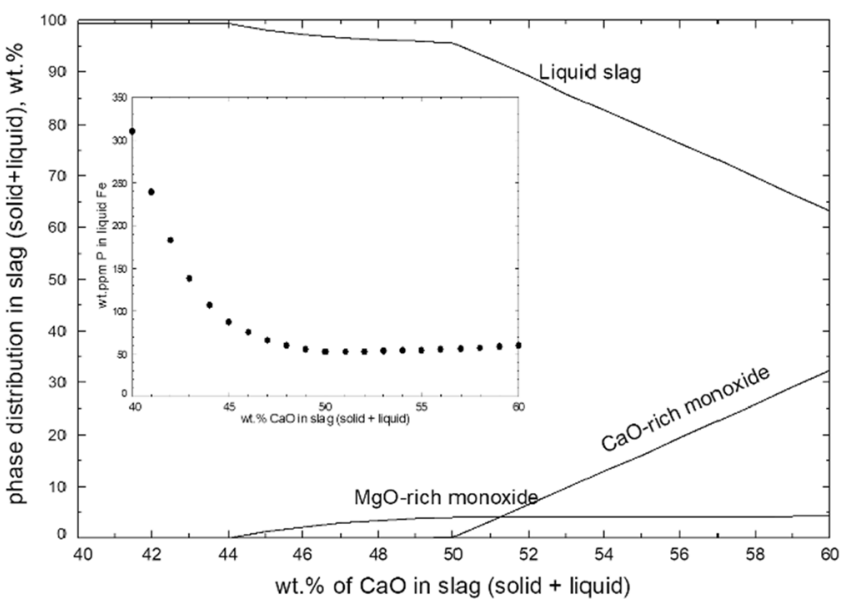

(b)

Fig. $10-(a) L_{\mathrm{P}}$ between molten iron and slag along the $\mathrm{CaO}$ saturation in the $\mathrm{CaO}-\mathrm{Fe}_{\mathrm{t}} \mathrm{O}-\mathrm{P}_{2} \mathrm{O}_{5}$ system (Figure reprinted with permission from Ref. [60], see details in the reference), and (b) changes in slag phase distribution and wt. ppm $\mathrm{P}$ in liquid Fe by the reaction between 100 ton of $\mathrm{Fe}-0.1$ pet $\mathrm{P}$ and 10 ton of slag $\left(\mathrm{CaO}-\mathrm{SiO}_{2}-25 \mathrm{FeO}-7 \mathrm{MgO}-2 \mathrm{Al}_{2} \mathrm{O}_{3}\right.$ in wt pet) with increasing the $\mathrm{CaO}$ content. FTmisc-FeLQ and FToxid databases are used in the calculations.

composition is about, in wt pet, $47 \mathrm{CaO}-25 \mathrm{FeO}-15-$ $\mathrm{SiO}_{2}-7 \mathrm{MgO}-2 \mathrm{P}_{2} \mathrm{O}_{5}-2 \mathrm{Al}_{2} \mathrm{O}_{3}-2 \mathrm{MnO}$. In order to understand the phosphorus removal in the BOF process, the most fundamental system is the $\mathrm{CaO}-\mathrm{Fe}_{\mathrm{t}} \mathrm{O}-\mathrm{P}_{2} \mathrm{O}_{5}$ system.

The phosphorus distribution $\left(L_{\mathrm{P}}=(\mathrm{pct} \mathrm{P})_{\mathrm{slag}} /[\mathrm{pct}\right.$ $\mathrm{P}]_{\mathrm{Fe}}$ ) between molten $\mathrm{Fe}$ and liquid slag saturated with solid $\mathrm{CaO}$ is calculated in Figure 10(a). It is very well known that $L_{\mathrm{P}}$ increases with increasing the $\mathrm{FeO}$ content up to about 15 to $20 \mathrm{wt}$ pct and then decreases with further increasing the $\mathrm{FeO}$ content. $L_{\mathrm{P}}$ increases with decreasing temperature at a given slag composition. The calculated $L_{\mathrm{P}}$ is in good agreement with experimental data (see Reference 60 for further information). Figure 10(b) shows a more realistic calculation for the BOF process. In the calculations, 100 ton of liquid $\mathrm{Fe}$ containing $0.1 \mathrm{wt}$ pct $\mathrm{P}$ was reacted with 10 ton of slag $\left(\mathrm{CaO}-\mathrm{SiO}_{2}-25 \mathrm{FeO}-7 \mathrm{MgO}-2 \mathrm{Al}_{2} \mathrm{O}_{3}\right.$ in wt pet) with an increasing $\mathrm{CaO}$ content in slag. The amount of solid slag
(CaO-rich phase, and $\mathrm{MgO}$-rich phase) increases with increasing the $\mathrm{CaO}$ amount and decreasing the $\mathrm{SiO}_{2}$ amount in slag. The $\mathrm{P}$ content in liquid steel decreases rapidly from 310 to $52 \mathrm{wt}$ ppm with increasing the $\mathrm{CaO}$ content in slag from 40 to 50 wt pct. Then, the P concentration increases steadily back to $60 \mathrm{wt}$ ppm until 60 wt pet of $\mathrm{CaO}$ in slag. This means that the best slag condition for de-phosphorization is a liquid slag with $\mathrm{CaO}$ saturation. When solid $\mathrm{CaO}$ phase forms, the de-P capacity decreases due to the decrease of the liquid slag amount where phosphate dissolves.

\section{Deoxidation Equilibria in High Mn Steel}

Deoxidation of liquid steel is one of the most important steps in the secondary steelmaking process. The deoxidation equilibria of high alloy steels such as new Twinning-Induced Plasticity (TWIP) steels has been 
less investigated. Therefore, accurate prediction of deoxidation equilibria using thermodynamic databases is necessary. Databases using the MQM to describe the liquid steel solution show much higher predictive ability than WIPF (UIPF) or BWRM-based databases. For example, Figure 11(a) shows the predicted Al deoxidation behavior of TWIP steel (Fe-18wt pct Mn) at 1600 ${ }^{\circ} \mathrm{C}$. The MQM can accurately predict the experimental deoxidation behavior, ${ }^{[61]}$ while the WIPF and the FTmisc-FeLQ databases (UIPF with associate mode $\left.{ }^{[37]}\right)$ are both over-estimating the oxygen content. The inclusion stability diagram of the Fe-Mn-Al-O system is also calculated ${ }^{[61]}$ in Figure 11(b) using the FSstel 8.0 database. The oxygen concentration in $\mathrm{Fe}-\mathrm{Mn}$ alloy by $\mathrm{Al}$ deoxidation is reasonably well predicted. Other deoxidation equilibria in low carbon steels and high alloy steels are also well predicted with the MQM.

\section{E. Heat Balance in the Alloying Process}

In high alloy steel production, the alloying agent is added mostly in the form of ferroalloys in the secondary steelmaking process. During alloying, the liquid steel temperature can decrease significantly as cold ferroalloy is added. Therefore, the exact heat balance calculation is very important to design the proper reheating schedule. For example, high Mn steel such as TWIP steel is produced by addition of FeMn alloy in the ladle furnace. In Figure 12(a), the temperature change of liquid steel initially at $1600{ }^{\circ} \mathrm{C}$ by addition of FeMn alloy at $25^{\circ} \mathrm{C}$ is calculated under adiabatic condition. That is, 100 tons of liquid $\mathrm{Fe}$ at $1600{ }^{\circ} \mathrm{C}+x$ tons of FeMn alloy (75Mn-24Fe-1C in wt pct) at $25^{\circ} \mathrm{C} \rightarrow(100$ $+x)$ tons of final steel: $\Delta \mathrm{H}=0$. According to the calculation, the steel temperature decreases drastically with increasing the $\mathrm{Mn}$ content in steel. The energy (yield $=100 \mathrm{pct}$ ) required to maintain the steel

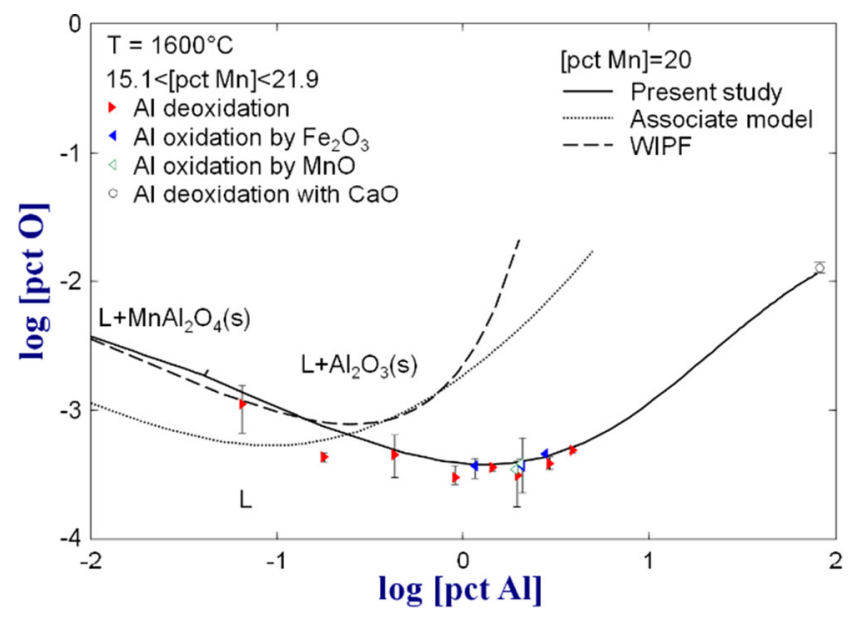

(a) temperature at $1600{ }^{\circ} \mathrm{C}$ can also be calculated as in Figure 12(b). Based on this result, the arcing schedule can be prepared.

\section{F. Degassing Process}

Degassing units such as RH degasser and Tank Degasser are frequently used in secondary steelmaking to remove carbon, nitrogen, and hydrogen. In the degassing process, alloying and deoxidation are often performed too. In high Mn steel production, degassing should be carefully controlled due to $\mathrm{Mn}$ evaporation. For example, the vapor pressure of alloying elements in liquid Fe-Mn-1.5Al(Si)-0.5C alloy steel (in wt pet) at $1600{ }^{\circ} \mathrm{C}$ is calculated in Figure 13. As can be seen, the $\mathrm{Mn}$ vapor pressure increases rapidly with increasing the Mn content in liquid steel. At 3wt pct Mn, the vapor pressure of $\mathrm{Mn}$ is about 1 torr. Therefore, degassing under vacuum for Mn steels containing more than $3 \mathrm{wt}$ pet Mn should be very carefully monitored to minimize the Mn loss by evaporation.

\section{G. Reoxidation During Casting}

Liquid steel reoxidation should be minimized as much as possible in the tundish and during continuous casting to reduce unexpected non-metallic inclusion formation and nozzle clogging. One source of reoxidation in the casting process is the Ar shield gas. Ar shield gas is typically applied around a submerged entry nozzle (SEN) to reduce air ingression. The Ar gas can be sucked through the porous SEN refractory material into the liquid steel due to the negative pressure produced by the high speed flow of liquid steel in the small diameter SEN. The SEN main body is made of $\mathrm{Al}_{2} \mathrm{O}_{3}-\mathrm{C}$ material. At high temperature, a chemical reaction between $\mathrm{Al}_{2} \mathrm{O}_{3}$ and $\mathrm{C}$ can take place, producing $\mathrm{CO}$ gas. Although the equilibrium $\mathrm{CO}$ pressure is less than 1 atm, due to the penetration of Ar gas through the nozzle, $\mathrm{CO}$ gas can be

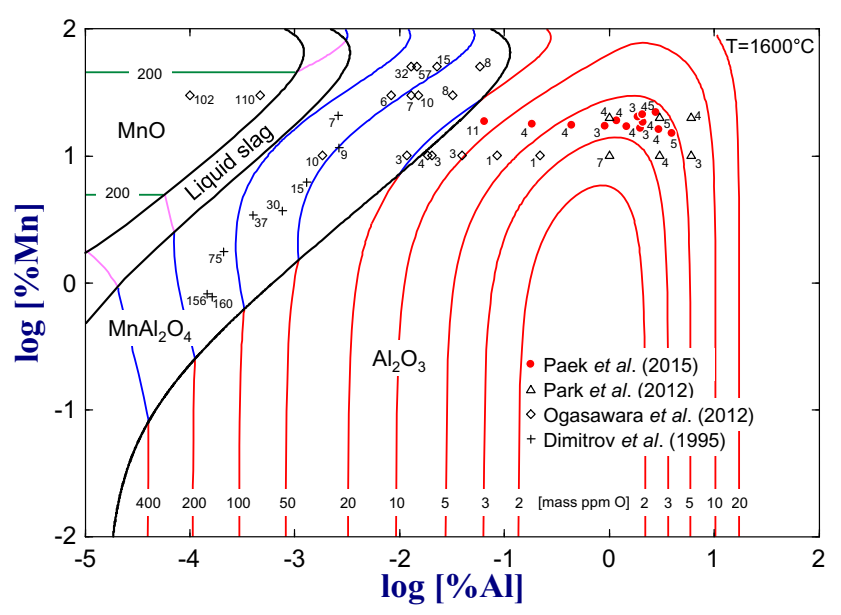

(b)

Fig. 11-Deoxidation of high Mn- and Al-killed steel at $1600{ }^{\circ} \mathrm{C}$, calculated using the FSstel 8.0 database (MQM for liquid steel solution) and FToxid database. (a) Calculated deoxidation equilibria in Fe-18wt pct $\mathrm{Mn}-\mathrm{Al}-\mathrm{O}$ liquid steel in comparison with calculations using the classical WIPF, and FTmisc-FeLQ database (UIPF and associate model). (b) Inclusion stability diagram of the Fe-Mn-Al-O system. 


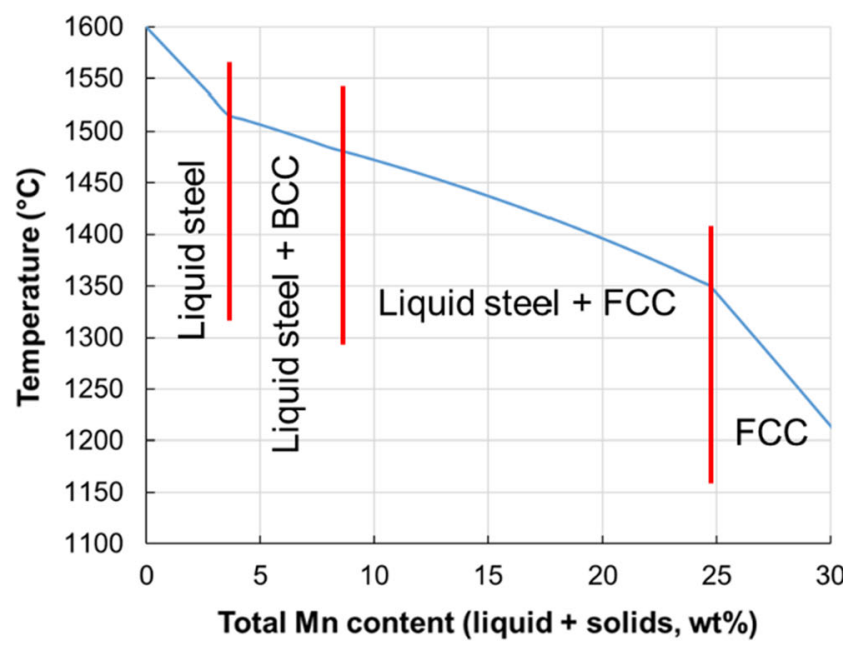

(a)

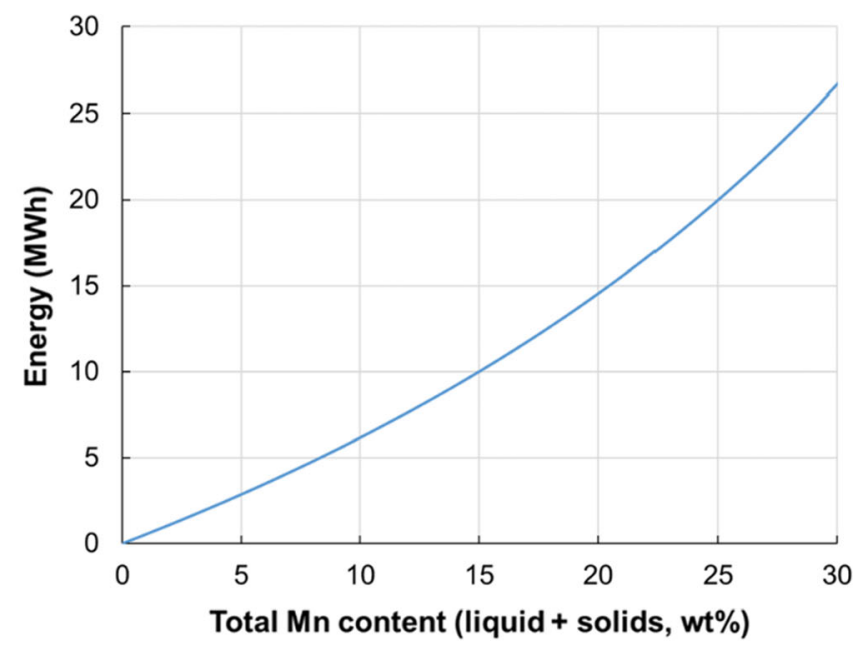

(b)

Fig. 12- Heat balance calculations for ladle furnace in high Mn steel production. (a) Temperature change under adiabatic condition, and (b) energy required (heating) to maintain the steel temperature at $1600{ }^{\circ} \mathrm{C}$. Initial condition: 100 tons of liquid $\mathrm{Fe}$ at $1600{ }^{\circ} \mathrm{C}+x$ tons of FeMn alloy (75Mn-24Fe-1C in wt pct) at $25^{\circ} \mathrm{C}$. Calculation was performed using FSstel database.

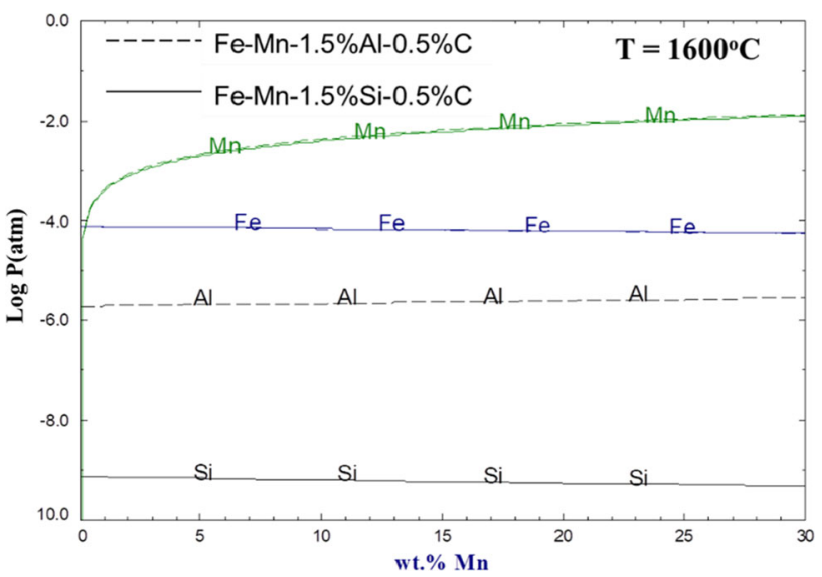

Fig. 13-Vapor pressure of alloying elements in liquid Fe-Mn-1.5Al(Si)-0.5C steel (in wt pct) at $1600{ }^{\circ} \mathrm{C}$. Calculation was performed using FSstel and FactPS databases.

produced in the surrounding Ar gas. The $\mathrm{CO}$ gas is then transported toward the steel and can reoxidize the Al-killed steel inside the SEN.

The schematic diagram of this reoxidation process is presented in Figure 14(a). CO gas can be produced by the internal reaction in the $\mathrm{Al}_{2} \mathrm{O}_{3}-\mathrm{C}$ refractory:

$$
2 \mathrm{Al}_{2} \mathrm{O}_{3}(\mathrm{~s})+9 \mathrm{C}(\mathrm{s})=\mathrm{Al}_{4} \mathrm{C}_{3}(\mathrm{~s})+6 \mathrm{CO}(\mathrm{g})
$$

The equilibrium partial pressure of $\mathrm{CO}, \mathrm{P}_{\mathrm{CO}}$, is calculated in Figure 14(b). It should be noted that this is the maximum $\mathrm{P}_{\mathrm{CO}}$, but in reality, $\mathrm{P}_{\mathrm{CO}}$ should be lower than this due to the reaction kinetics. Considering that the nozzle temperature would be lower than liquid steel itself, the maximum $\mathrm{P}_{\mathrm{CO}}$ in Ar gas would be about $10^{-3}$ atm. The reoxidation equilibria of various liquid steels by $\mathrm{CO}$ gas are calculated in Figures 14(c) through (f) at temperatures ranging from $1550{ }^{\circ} \mathrm{C}$ to $1450{ }^{\circ} \mathrm{C}$. The main reoxidation reaction can happen through:

$$
3 \mathrm{CO}(\mathrm{g})+2[\mathrm{Al}]=\mathrm{Al}_{2} \mathrm{O}_{3}(\mathrm{~s})+3[\mathrm{C}]
$$

For example, for low carbon steel at $1550{ }^{\circ} \mathrm{C}$ in Figure 14(c), liquid steel containing about 0.04 pct [Al] can be reoxidized until $[\mathrm{Al}]=0.001 \mathrm{wt}$ pct under $\mathrm{P}_{\mathrm{CO}}=$ $10^{-3} \mathrm{~atm}$. In the case of Ti-bearing Al-killed steel in (d), solid $\mathrm{Al}_{2} \mathrm{O}_{3}$, liquid $\mathrm{Al}_{2} \mathrm{O}_{3}-\mathrm{TiO}_{2}-\mathrm{Ti}_{2} \mathrm{O}_{3}$, and solid Ti oxide inclusions can be formed. ${ }^{[62]}$ It is well known that Ti-bearing Al-killed steel is prone to nozzle clogging. Recently, Lee et al. ${ }^{[63]}$ experimentally proved that the Ti-bearing Al-killed steel can be reoxidized by $\mathrm{CO}$ gas.

On the other hand, as can be seen in Figures 14(e) and (f), liquid TWIP steel with $20 \mathrm{wt}$ pct $\mathrm{Mn}$ and $0.5 \mathrm{wt}$ pct $\mathrm{C}$ is barely reoxidized under $\mathrm{P}_{\mathrm{CO}}=10^{-3} \mathrm{~atm}$. This means that TWIP steel with 1.5 pct $\mathrm{Al}$ or 1.5 pct $\mathrm{Si}$ is less prone to nozzle clogging. In fact, this lower reoxidation tendency is due to the high $\mathrm{C}$ content in TWIP steel. As can be understood by Reaction [7], the reoxidation by $\mathrm{CO}$ gas can be retarded by a high $\mathrm{C}$ content in liquid steel.

\section{H. AlN Formation During Casting}

$\mathrm{AlN}$ inclusions forming in the steel casting process is generally bad for the steel quality. AlN can react with mold flux and produce $\mathrm{N}_{2}$ bubbles, which can be trapped at the surface of the steel slab in the continuous casting process:

$$
4 \mathrm{AlN}(\mathrm{s})+3\left(\mathrm{SiO}_{2}\right)=2\left(\mathrm{Al}_{2} \mathrm{O}_{3}\right)+2 \mathrm{~N}_{2}(\mathrm{~g})+3[\mathrm{Si}]
$$

Agglomeration of AlN inclusions in liquid steel can deteriorate the mechanical properties of the final product. In particular, high $\mathrm{Mn}$ steels can dissolve more nitrogen in liquid state and can cause more AIN formation during the casting process unless nitrogen is well controlled. 
Reoxidation of liquid steel in SEN

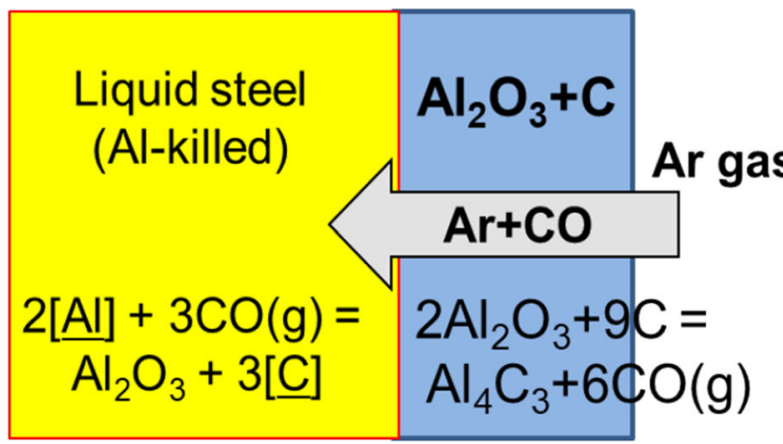

(a)

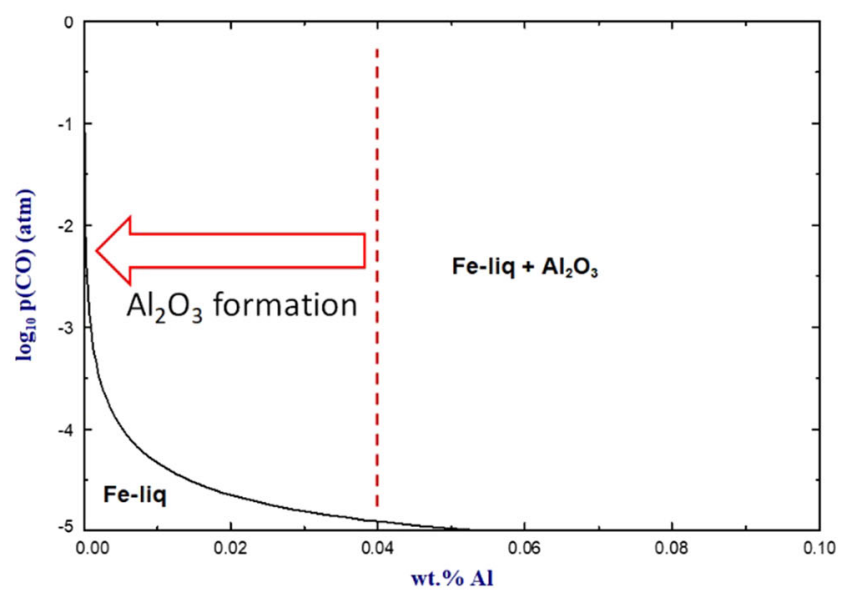

(c)

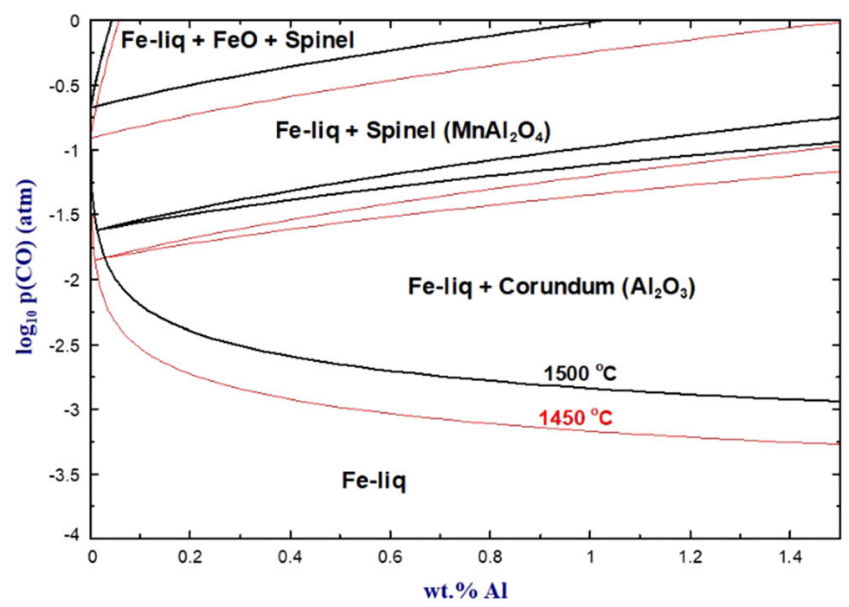

(e)

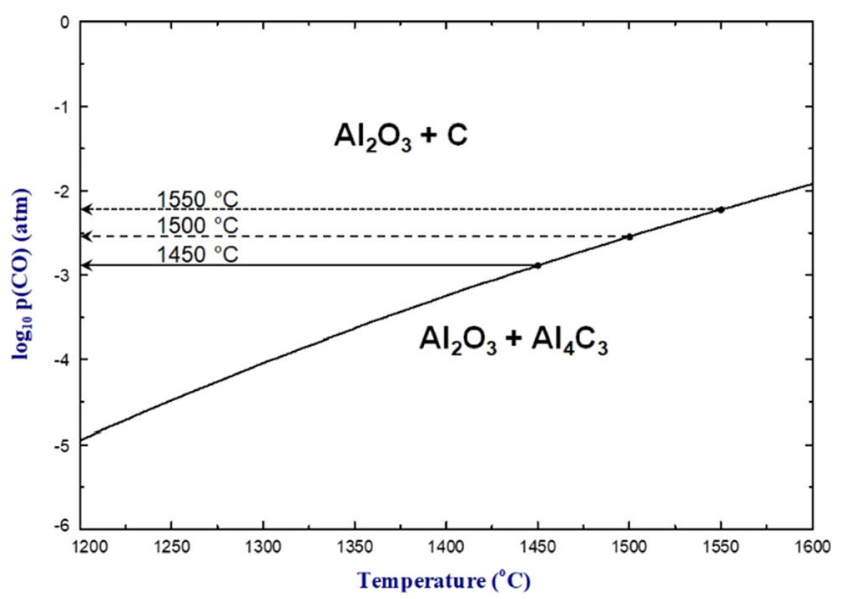

(b)

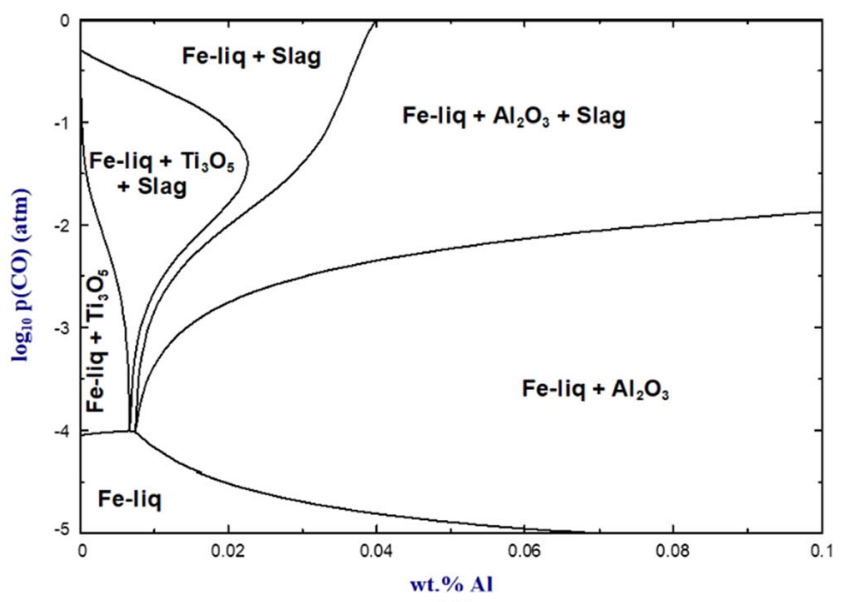

(d)

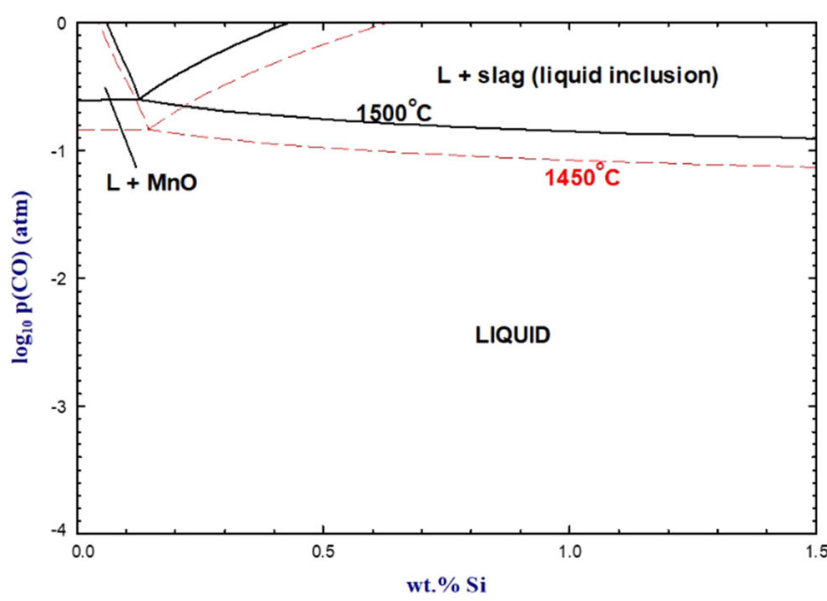

(f)

Fig. 14 - Reoxidation of liquid steel by the $\mathrm{CO}$ gas in a submerged entry nozzle (SEN) during the casting process. (a) schematic diagram for reoxidation process, (b) equilibrium $\mathrm{P}_{\mathrm{CO}}$ produced by $\mathrm{Al}_{2} \mathrm{O}_{3}-\mathrm{C} \mathrm{SEN}$ refractory, and $\mathrm{Al}_{2} \mathrm{O}_{3}$ formation by $\mathrm{CO}$ gas in $(c)$ liquid $\mathrm{Fe}$ at $1550{ }^{\circ} \mathrm{C}$, $(d)$ liquid Fe containing $0.1 \mathrm{wt}$ pet $\mathrm{Ti}$ at $1550{ }^{\circ} \mathrm{C},(e)$ and $(f)$ liquid $\mathrm{Fe}-20 \mathrm{Mn}-0.5 \mathrm{C}-\mathrm{Al}$ (or Si) (in wt pet) at $1500{ }^{\circ} \mathrm{C}$ and $1450{ }^{\circ} \mathrm{C}$. Calculations were performed using FactPS, FSstel, FTmisc-FeLQ and FToxid databases.

The nitrogen solubility in liquid steel is very well predicted from the MQM with only binary parameters as demonstrated in the previous study. ${ }^{[64]}$ This new description of nitrogen is stored in FactSage FSstel database. Figure 15(a) shows the equilibrium solubility limits of $[\mathrm{N}]$ in high $\mathrm{Mn}$ steel at $1450{ }^{\circ} \mathrm{C}$ to $1550{ }^{\circ} \mathrm{C}$ depending on the $\mathrm{Al}$ content. The predicted solubility limits from the FSstel database are in good agreement with experimental data. The AlN formation from liquid Fe-20Mn-0.6C-1.5Al-0.3Si-N steel during the casting 
process is calculated in Figure 15(b) (Scheil cooling calculations). When the dissolved $\mathrm{N}$ content is more than $40 \mathrm{wt}$ ppm, solid AlN inclusions can be generated prior to the formation of fcc phase. These inclusions can easily agglomerate and deteriorate the surface quality of steel.

\section{Solidification of Mold Flux}

The three most important roles of the mold flux in the continuous casting process are (i) lubrication to reduce friction between the water-cooled $\mathrm{Cu}$ mold and steel slab, (ii) heat flux control for a sound solidification of steel, and (iii) protection of liquid steel from reoxidation and removal of inclusions. For the first two aspects, the crystallization behavior and viscosity of mold flux are very important.

Conventional mold flux is composed of the $\mathrm{CaO}$ $\mathrm{SiO}_{2}-\mathrm{Na}_{2} \mathrm{O}-\mathrm{CaF}_{2}$ system, where considerable amounts of $\mathrm{CaF}_{2}$ and $\mathrm{Na}_{2} \mathrm{O}$ are added. As mold flux is an oxy-fluoride system, phase diagrams are complex and thermodynamic databases are difficult to develop. In FactSage FToxid database, the oxy-fluoride system including the $\mathrm{CaO}-\mathrm{MgO}-\mathrm{Al}_{2} \mathrm{O}_{3}-\mathrm{SiO}_{2}-\mathrm{Na}_{2} \mathrm{O}-\mathrm{K}_{2} \mathrm{O}$ $\mathrm{Li}_{2} \mathrm{O}-\mathrm{F}$ system is well described for mold flux and special refining flux applications.

Figure 16 shows phase diagram sections of the $\mathrm{CaO}-\mathrm{SiO}_{2}-\mathrm{Na}_{2} \mathrm{O}-\mathrm{CaF}_{2}$ mold flux system. The diagrams illustrate the influence of $\mathrm{Na}_{2} \mathrm{O}$ (10 and $15 \mathrm{wt}$ pct) and $\mathrm{CaF}_{2}$ (15 and $20 \mathrm{wt}$ pct) content on the primary and secondary crystallization temperature of the mold flux depending on the mold flux basicity (ratio $\mathrm{CaO} / \mathrm{SiO}_{2}$ the $x$-axis is in $\mathrm{SiO}_{2}$ content in the diagram). As well known, the cuspidine phase $\left(\mathrm{Ca}_{4} \mathrm{Si}_{2} \mathrm{~F}_{2} \mathrm{O}_{7}\right)$ is the most important primary crystalline phase in the conventional mold fluxes. As can be seen, the primary crystallization temperature of cuspidine has maximum at about 38 to 42 pct of $\mathrm{SiO}_{2}$. It decreases with increasing the $\mathrm{Na}_{2} \mathrm{O}$ content: 5 pct additional $\mathrm{Na}_{2} \mathrm{O}$ can decrease the crystallization temperature by about $40 \mathrm{~K}$. The $\mathrm{CaSiO}_{3}$ crystallization can be largely influenced by $\mathrm{CaF}_{2}: 5$ pct more $\mathrm{CaF}_{2}$ can decrease crystallization temperature of $\mathrm{CaSiO}_{3}$ by about $50 \mathrm{~K}$. The crystallization temperature of secondary phase (combeite phase; $\mathrm{Na}_{2} \mathrm{Ca}_{2} \mathrm{Si}_{3} \mathrm{O}_{9}$ solid solution) can be also largely influenced by $\mathrm{CaF}_{2} .5 \mathrm{pct}$ additional $\mathrm{CaF}_{2}$ can decrease the crystallization temperature by about $40 \mathrm{~K}$. The crystallization behavior of a commercial mold flux is calculated in Figure 17. The calculated result is in an excellent agreement with in-house experimental data by Tata Steel Europe.

The phase diagram and solidification profiles of the mold flux depending on flux composition are very helpful for new mold flux design. Recently, steelmakers successfully apply the FToxid database to the development of new suitable mold fluxes for new steel grades. The viscosity database can be also used to calculate accurate viscosity of oxy-fluoride flux.

\section{J. Casting of Steel: Scheil Cooling Calculation}

Conventional low carbon steel has a narrow solidification temperature range, so it is relatively easy to control the solidification. However, high alloy steels typically have long solidification ranges, and sometime follow a peritectic solidification, which causes difficulties in the continuous casting practice.

For example, the liquidus projection of high Mn steel (Fe-Mn-C-1.5wt pct Al) and Scheil cooling of TWIP steel $(\mathrm{Fe}-20 \mathrm{Mn}-1.5 \mathrm{Al}-0.5 \mathrm{C}$ in wt pct) are calculated in Figure 18 with the FSstel database. In the Scheil cooling calculation, the mains assumptions are complete diffusion and equilibrium in the liquid phase, and no diffusion in solid phases. In reality, a certain degree of back diffusion in solid phases can happen in the casting process, typically resulting in an overestimation of the liquid phase amount with Scheil cooling calculations. Nevertheless, the solidification microstructure can be reasonably captured with Scheil calculation. As can be seen in the Scheil cooling calculation, the solidification range of TWIP steel is more than $250^{\circ} \mathrm{C}$. Therefore, it is

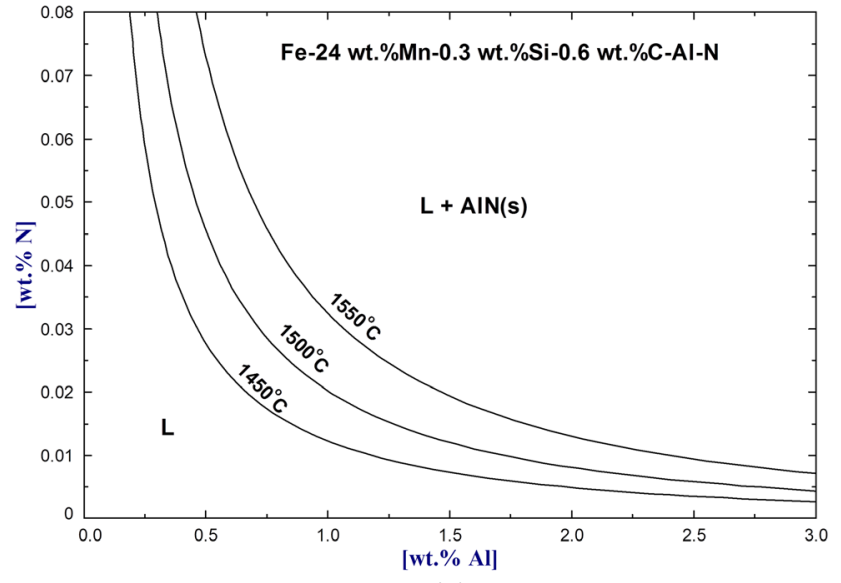

(a)

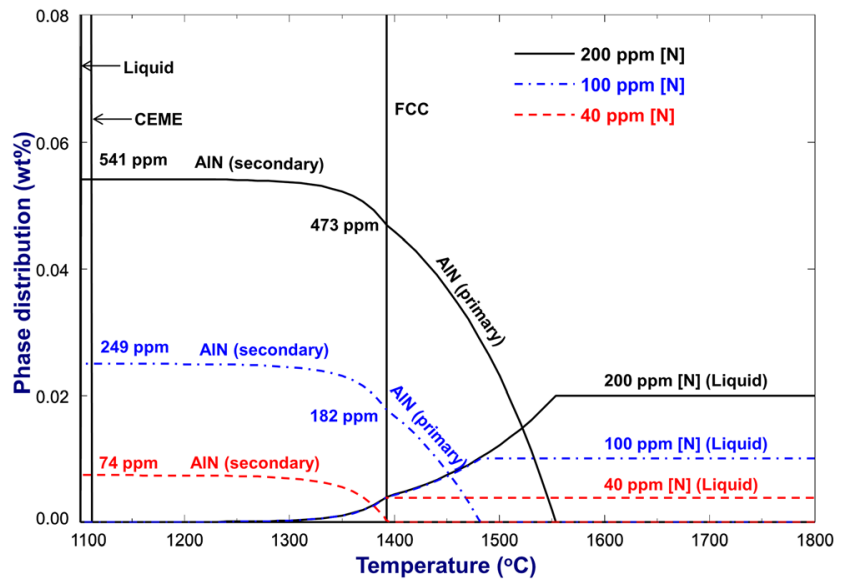

(b)

Fig. 15 - (a) Solubility limit of nitrogen in high Mn liquid steel depending on Al content (see Ref. [64] for the experimental data), and (b) AlN formation during the casting process depending on the dissolved $[\mathrm{N}]$ content in high $\mathrm{Mn}$ steel. 
$10 \mathrm{wt} \% \mathrm{Na}_{2} \mathrm{O}$
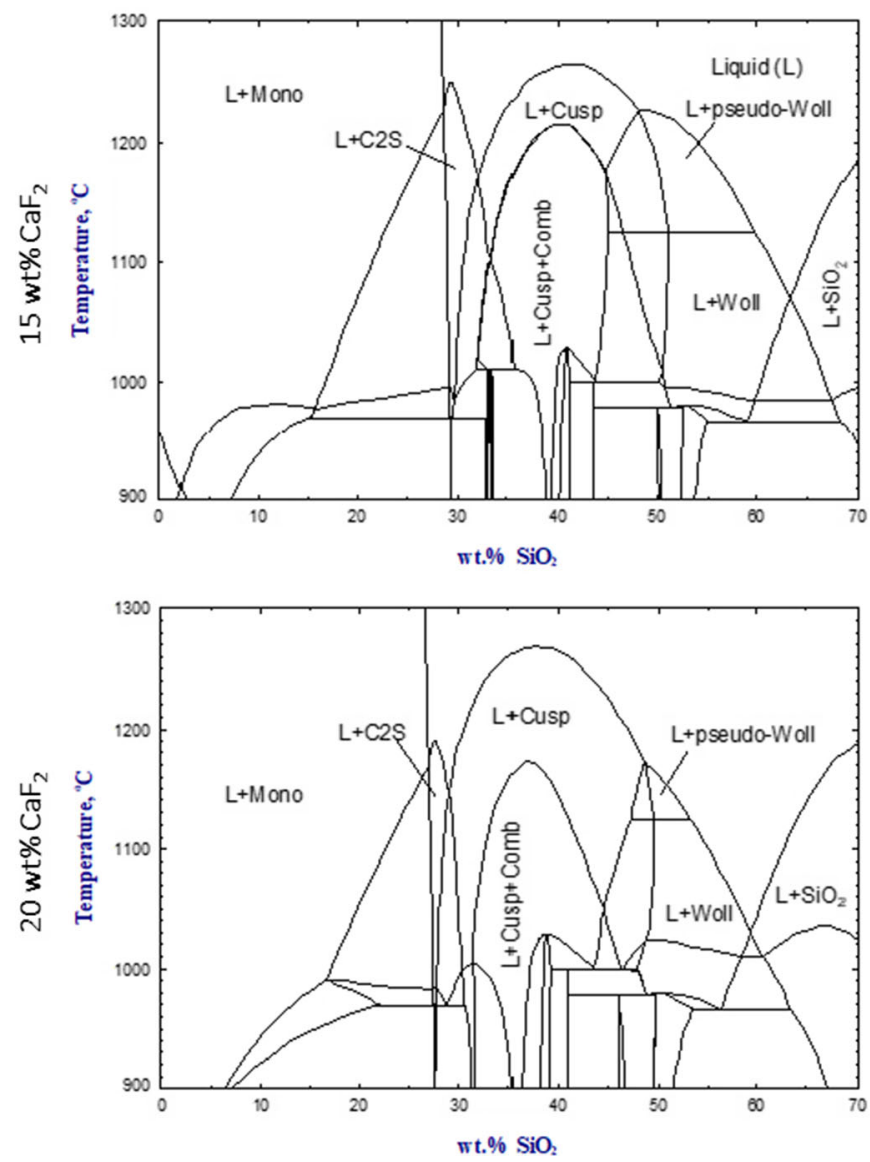

15 wt\% $\mathrm{Na}_{2} \mathrm{O}$
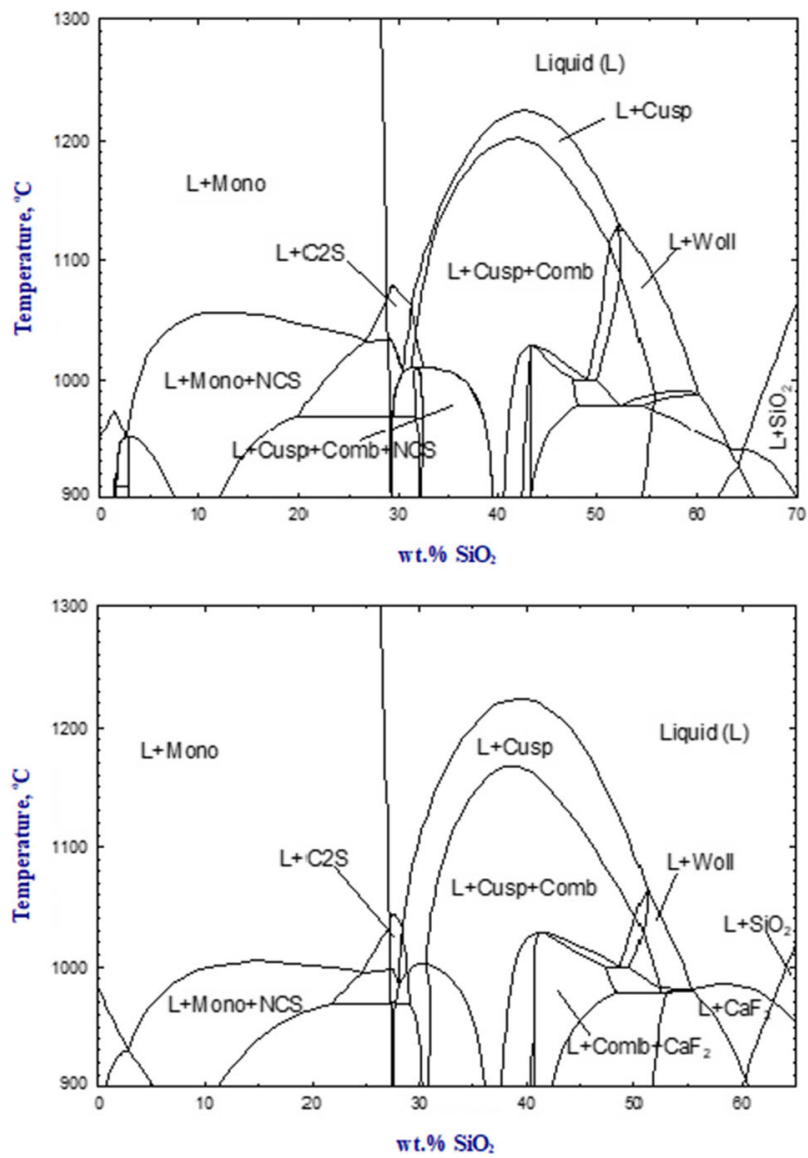

Fig. 16- Phase diagrams of the $\mathrm{CaO}-\mathrm{SiO}_{2}-\mathrm{Na}_{2} \mathrm{O}-\mathrm{CaF}_{2}$ mold flux system calculated from FToxid database. Cusp $=\mathrm{Cuspidine}\left(\mathrm{Ca}_{4} \mathrm{Si}_{2} \mathrm{~F}_{2} \mathrm{O}_{7}\right)$, $\mathrm{Comb}=$ Combeite $\left(\mathrm{Na}_{2} \mathrm{Ca}_{2} \mathrm{Si}_{3} \mathrm{O}_{9}\right.$ solid solution), Mono: $\mathrm{CaO}$-rich monoxide, $\mathrm{C} 2 \mathrm{~S}=\mathrm{Ca}_{2} \mathrm{SiO}_{4}$-rich solid solution, Woll and pseudo-Woll $=$ $\mathrm{CaSiO}_{3}$ solids, and $\mathrm{NCS}=\mathrm{Na}_{2} \mathrm{CaSiO}_{4}$.

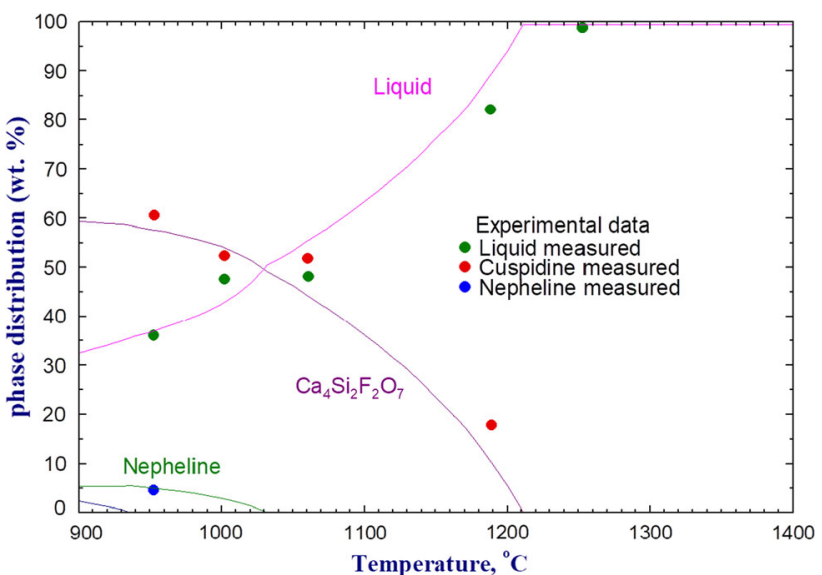

Fig. 17-Crystallization of mold flux 26.2 CaO-33.6 $\mathrm{SiO}_{2}-9.2$ $\mathrm{Na}_{2} \mathrm{O}-22.3 \mathrm{CaF}_{2}-4.4 \mathrm{MgO}-3.8 \mathrm{Al}_{2} \mathrm{O}_{3}$ in wt pet. Thermodynamic calculation performed with FToxid database and experimental data are provided by Tata Steel Europe.

very difficult to produce a slab of sound internal and surface quality with conventional continuous casting operations.

\section{K. New High Alloyed Steel Including Ordered Phase}

Recently, new high alloyed steels utilizing BCC_B2 precipitates were developed. ${ }^{[65]}$ When sub-micron sized BCC_B2 precipitates are well spread in the matrix, the tensile strength of the alloy was improved to a level comparable to that of titanium alloy. The key of this alloy design is the proper control of $\mathrm{Al}$ and $\mathrm{Ni}$ to produce the $\mathrm{BCC}_{-} \mathrm{B} 2$ phase. As known, very stable BCC_B2 ordered phase is formed in the Al-Ni system. Therefore, a proper amount of $\mathrm{Al}$ and $\mathrm{Ni}$ in the Fe system can promote the BCC_B2 phase formation. These BCC_B2 and FCC_L12 (ordered FCC) phases relevant to the steel industry are properly described in the FSstel database.

Figure 19(a) shows the phase diagram of the Fe$16 \mathrm{Mn}-10 \mathrm{Al}-5 \mathrm{Ni}-\mathrm{C}$ system. The alloys in this system follow the peritectic solidification. The stability range of BCC_A2 (disordered BCC) and FCC_A1 (disordered FCC) phases varies significantly with the carbon content. In addition, the kappa-carbide formation temperature increases rapidly with the carbon content. The phase evolution during equilibrium cooling of the alloy Fe-16Mn-10Al-5Ni-0.86C in wt pet is calculated in Figure 19(b). This is the composition corresponding to 


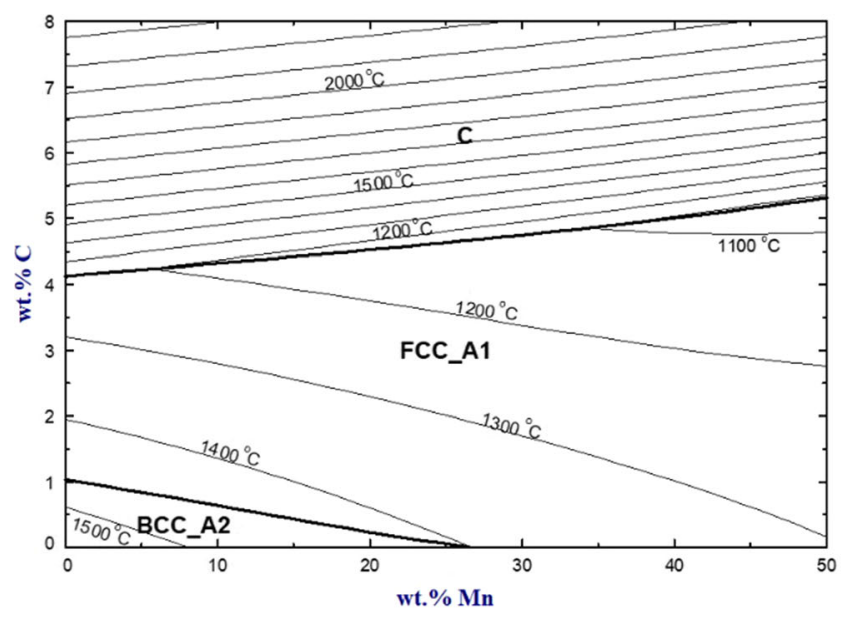

(a)

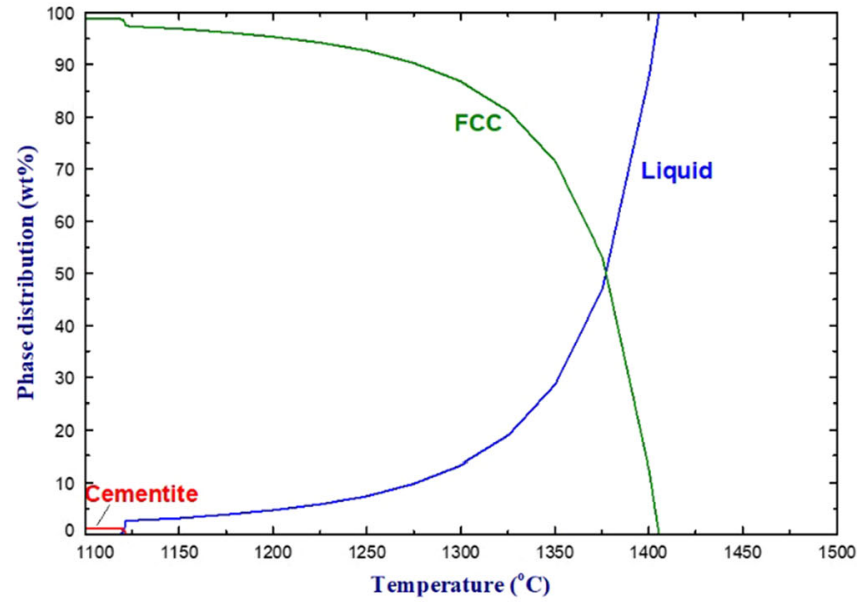

(b)

Fig. 18-(a) Liquidus projection of the Fe-Mn-C-1.5wt pct Al system, and (b) Scheil cooling of TWIP steel (Fe-20wt pct Mn-1.5wt pct Al-0.5wt pct $\mathrm{C}$ alloy). Calculations were performed using the FSstel database.

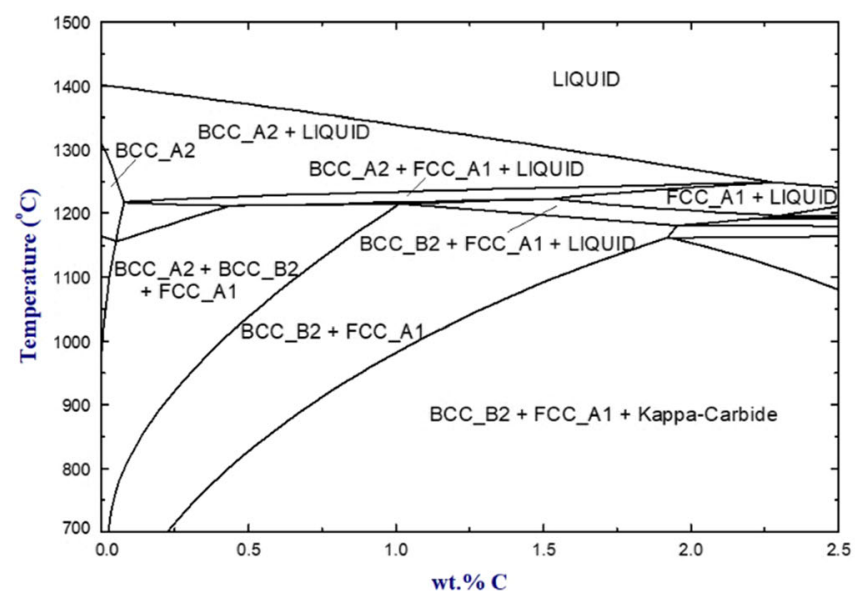

(a)

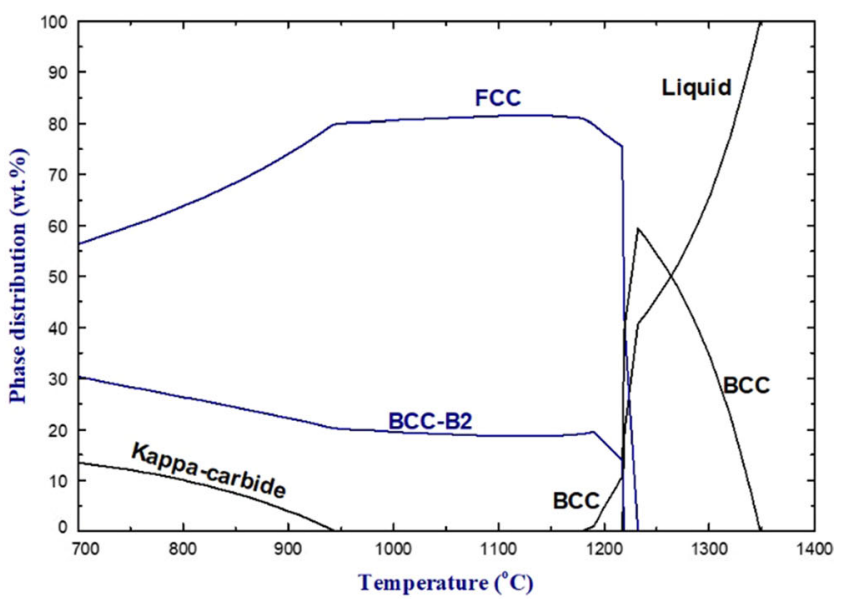

(b)

Fig. 19-(a) Phase diagram of the Fe-16Mn-10Al-5Ni-C system (in wt pct), and (b) equilibrium phase distributions of Fe-16Mn-10Al-5Ni-0.86C alloy (in wt pct) with temperature. Calculations were performed using the FSstel database.

the new ultra high strength alloy reported by Kim et al. ${ }^{[65]}$ Upon solidification, a considerable amount of BCC_B2 phase has already formed above $1000{ }^{\circ} \mathrm{C}$, which is represented as a large band type of BCC_B2 phase by Kim et al. The sub-micron sized BCC_B2 ordered phase, which plays in fact a key role in the strength hardening, was produced in the FCC_A1 matrix after shear deformation below $800{ }^{\circ} \mathrm{C}$. According to the equilibrium calculation, kappa-carbide forms at this temperature. If the formation of kappa-carbide is suppressed by its slow precipitation kinetics, however, the formation of the $\mathrm{BCC}$ B $\mathrm{B} 2$ ordered phase is predicted in FCC_A1 at deformation temperature below $800{ }^{\circ} \mathrm{C}$. This can explain the formation of sub-micron sized BCC_B2 precipitates. Thermodynamic databases built with reliable descriptions of alloy systems such as the FSstel database provides a remarkable tool to develop and design new ultra high strength alloys, avoiding the need for the trial and error approach.

\section{Zn Galvanizing Coating and New Coating}

Hot-dip galvanizing coating is always applied to high strength steels for the automotive industry. The conventional coating system is $\mathrm{Zn}$ containing very small amount of Al. In the recent years, the demand for galvanized steel sheets with greater corrosion resistance increases, and new coating materials have been developed. One of the most promising coating materials is the $\mathrm{Zn}-\mathrm{Al}-\mathrm{Mg}$ coating because $\mathrm{Mg}$ is known to enhance the corrosion resistance. Coating alloy composition can change the microstructure of the coating layer, which can significantly influence the corrosion resistance. For example, it is reported that the change of primary solid phase from $\mathrm{Zn}$ to $\mathrm{MgZn}_{2}$ (or $\mathrm{Mg}_{2} \mathrm{Zn}_{11}$ ) might deteriorate the corrosion resistance of the $\mathrm{Zn}-\mathrm{Al}-\mathrm{Mg}$ coating. ${ }^{[66]}$ 
The solidification microstructure of alloys can be estimated from liquidus projection and Scheil cooling calculations. Figure 20(a) shows the calculated liquidus projection of the $\mathrm{Zn}$-rich region of the $\mathrm{Zn}-\mathrm{Al}-\mathrm{Mg}$ system. The Scheil cooling calculation (assuming complete diffusion in liquid and no diffusion in solid phases) for the $\mathrm{Zn}-4 \mathrm{Al}-3 \mathrm{Mg}$ alloy (known as Zagnelis ${ }^{\mathrm{TM}}$ ) is presented in Figure 20(b). Both diagrams in Figure 20 were obtained using the FSstel database. According to the experimental results from Arcelor-Mittal, ${ }^{[67]}$ the as-solidified microstructure of Zagnelis is mainly composed of the $\mathrm{Zn} / \mathrm{Al} / \mathrm{MgZn}_{2}$ eutectic structure. However, the Scheil cooling calculation and liquidus diagram in Figure 20 reveal that the $\mathrm{Mg}_{2} \mathrm{Zn}_{11}$ phase can be one of the major constituents of the as-solidified microstructure of Zagnelis. If the crystallization of $\mathrm{Mg}_{2} \mathrm{Zn}_{11}$ is less favored during the solidification process, the eutectic structure $\mathrm{Zn} / \mathrm{Al} / \mathrm{MgZn}_{2}$ can be expected. The as-solidified microstructure of alternative coating systems like Al-Mg-Si alloys can also be well understood using thermodynamic calculations.

\section{Oxidation in Galvanizing Furnace}

The oxidation of high strength steels (Fe-Mn-Si-Al-C) in the annealing furnace prior to the $\mathrm{Zn}$ galvanizing coating process cannot be prevented even under $\mathrm{N}_{2}-\mathrm{H}_{2}$ gas mixture with low dew point temperature control. The presence of oxides on the steel surface can influence drastically the metallic coating quality. Therefore, the oxidation behavior of steel under reducing conditions at the annealing furnace has been a long-time issue for the galvanizing process.

Oxidation of Fe-1.5 pct Mn-1.5 pct Si-0.08 pct C steel is calculated in Figure 21(a). The partial pressure of $\mathrm{O}_{2}$ in the $\mathrm{N}_{2}-10$ pct $\mathrm{H}_{2}$ gas mixture prepared at dew points ranging from $-10{ }^{\circ} \mathrm{C}$ to $-40{ }^{\circ} \mathrm{C}$ is also plotted in the figure as dotted lines. Even when gas with a dew point of $-40{ }^{\circ} \mathrm{C}$ is applied in the annealing furnace, oxidation of steel cannot be prevented. The predicted primary oxide (the first oxide forming at the surface) is $\mathrm{MnSiO}_{3}$ at $T<$ $890{ }^{\circ} \mathrm{C}$, and $\mathrm{SiO}_{2}$ at $T>890{ }^{\circ} \mathrm{C}$. The primary oxidation diagram of $\mathrm{Fe}-\mathrm{Mn}-\mathrm{Si}-0.1 \mathrm{wt}$ pct $\mathrm{C}$ steel is calculated in Figure 21(b). Thick lines represent the phase boundaries of primary oxide phases. The stable metallic phase and primary oxide phase are indicated in each region of the diagram. Thin lines provide the minimum oxygen partial pressure for the oxide formation at each composition. In the case of the Fe-0.002 pct C-1.5 pct Mn- 1.5 pct Si steel at $800{ }^{\circ} \mathrm{C}$ (see Figure 6(a)), for example, the metallic phase is $\mathrm{BCC}$, and the primary oxide phase is $\mathrm{MnSiO}_{3}$ which can be oxidized even at $\left.\log \left(\mathrm{P}_{(} \mathrm{O}_{2}\right)\right)=-28.4$. That is, in order to prevent any oxidation of the steel, $\log \left(\mathrm{P}\left(\mathrm{O}_{2}\right)\right)$ should be controlled below -28.4. Thus, this type of diagrams can provide useful information on the oxide forming as primary oxidation product depending on the alloy composition at a given temperature. More details can be found in reference. ${ }^{[68]}$

\section{PROCESS SIMULATION AND SMART FACTORY}

\section{A. Effective Equilibrium Reaction Zone (EERZ) Model}

As thermodynamic databases are accurate and extensive enough for industrial problem solving, the databases have been utilized to simulate industrial processes, which are strictly speaking not in equilibrium state. In order to calculate the transient state problem in an industrial process, thermodynamics and mass transfer can be coupled. The reaction kinetics at the interface between two phases such as liquid slag and molten steel is highly dependent on the mass transfer of species at the interface. Local thermodynamic equilibrium is typically assumed at the interface. That is, the kinetics in the material process is highly depending on the local equilibrium zone size. The present authors have proposed the Effective Equilibrium Reaction Zone (EERZ) Model $^{[69]}$ to couple the mass transfer kinetics with

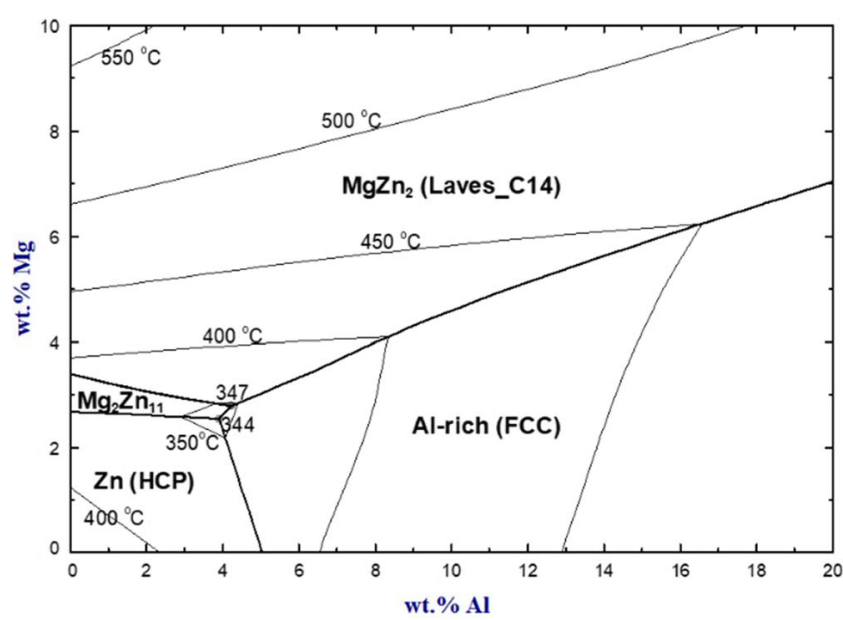

(a)

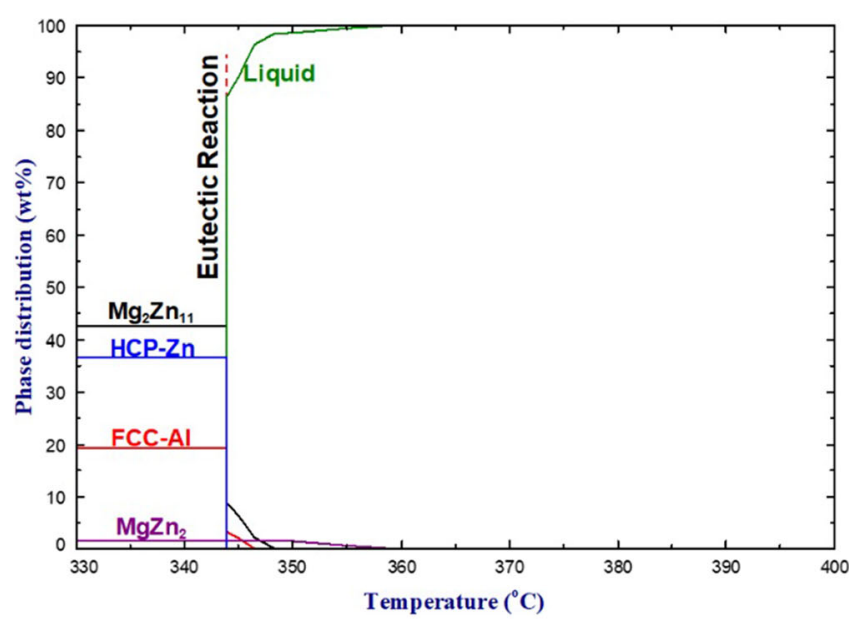

(b)

Fig. 20 - (a) Liquidus projection of the $\mathrm{Zn}$-rich region of the $\mathrm{Zn}-\mathrm{Al}-\mathrm{Mg}$ system, and (b) Scheil cooling calculation for the $\mathrm{Zn}-4 \mathrm{Al}-3 \mathrm{Mg}$ alloy. Calculations were performed using the FSstel database. 


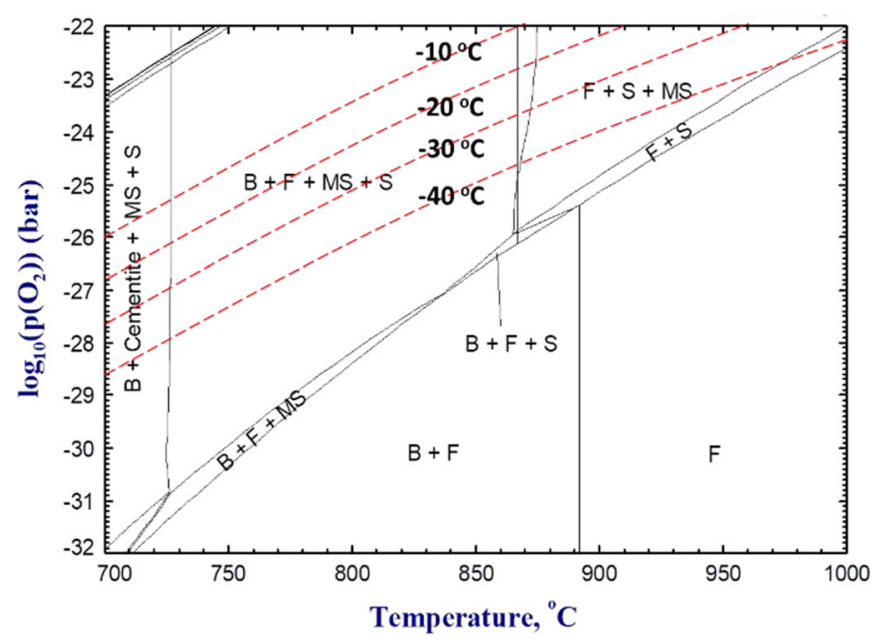

(a)

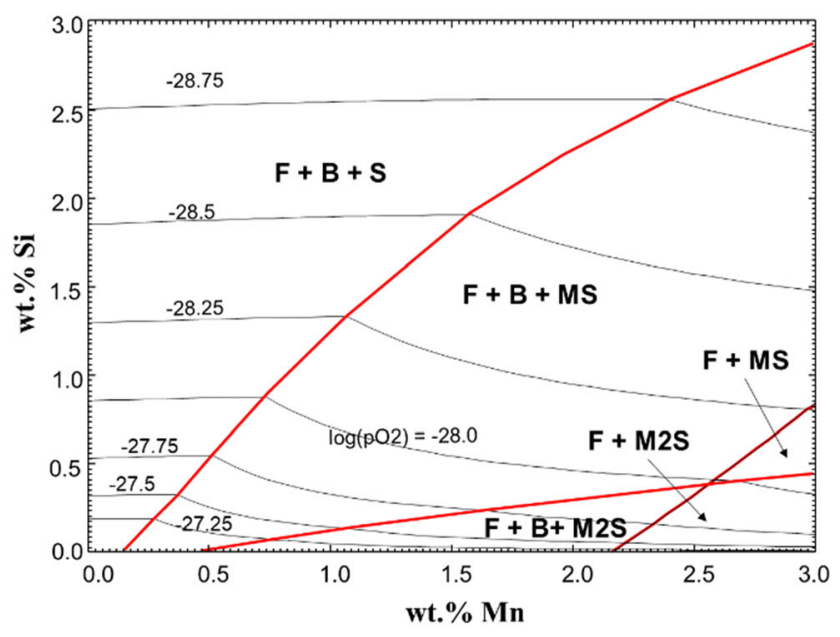

(b)

Fig. $21-(a)$ Oxidation diagram of Fe-1.5 pct Mn-1.5 pct Si-0.08 pet $\mathrm{C}$ with temperature. Dotted lines are $\mathrm{O}_{2}$ partial pressure contours of the $\mathrm{N}_{2}-10$ pct $\mathrm{H}_{2}$ gas mixture prepared at different dew points. (b) Primary oxidation phase diagram of Fe-Mn-Si- 0.1 pct C steel at $800{ }^{\circ} \mathrm{C}$. B, F, M, $\mathrm{S}$ and $\mathrm{A}$ stand for $\mathrm{BCC}, \mathrm{FCC}, \mathrm{MnO}, \mathrm{SiO}_{2}$ and $\mathrm{Al}_{2} \mathrm{O}_{3}$, respectively. The calculations were performed using FToxid and FSstel databases.

thermodynamic databases to simulate high temperature materials processes. The concept is represented in Figure 22.

In the EERZ model, a complex process is divided in a finite number of reaction zones in which equilibrium are calculated. As shown in Figure 22, for instance, in the simplified case of a slag/liquid metal reaction, the metal phase would be divided in a bulk volume (V3) and a smaller volume near the slag/metal interface (V1). The slag phase would be divided in a similar way (V4 and V2). In the EERZ Model, the equilibrium would be first calculated between V1 and V2, followed by equilibrium homogenization reactions in the metal phase (between $\mathrm{V} 1$ and V3) and in the slag phase (between V2 and V4). The local equilibrium zone sizes (V1 and V2 in Figure 22) at a given time step can be determined by the overall mass transfer coefficient and interface area. Of course, the mass transfer coefficients (and interface area) will vary with the process conditions and are typically expressed using the mixing energy in case of gas stirred vessels. During the chemical reactions at the interface, a certain amount of heat may be generated or absorbed, which can be directly calculated using the thermodynamic database. A certain amount of energy may be supplied to the system by an external source (arcing). Heat loss from the system to its surroundings (refractory, atmosphere, etc.) can also be considered. All these energy aspects can easily be taken into account in the process simulation using the EERZ model. Mass transfer coefficients may also strongly vary with the viscosity of materials (for example, liquid slag), which can be readily included in the EERZ model.

One of the drawbacks of the EERZ model would be the assumption of an overall mass transfer coefficient for all constituents of a given phase instead of individual mass transfer coefficient for each constituent. Although the mass transfer coefficient of each element is different, most elements in the liquid metallic phase could have similar coefficient because the latter depends significantly on the fluid dynamics in strong stirring conditions. In the case of slag, the diffusion coefficient of each slag component can be very different. If the reactor is very stagnant, considering the individual diffusion coefficient of each component of the liquid slag may be more appropriate. For example, diffusion coefficients of $\mathrm{CaO}$ and $\mathrm{SiO}_{2}$ can be very different in liquid slag. Fortunately, in most metallurgical processes involving a slag/metal interface, the reaction $(\mathrm{CaO})=[\mathrm{Ca}]+[\mathrm{O}]$ at the slag/metal interface hardly occurs because $\mathrm{CaO}$ is a very stable oxide. The main reaction (oxidation/reduction reaction depending on the slag and metal composition) is $\mathrm{SiO}_{2}=[\mathrm{Si}]+2[\mathrm{O}]$, or $3 \mathrm{SiO}_{2}+4[\mathrm{Al}]=3[\mathrm{Si}]$ $+2\left(\mathrm{Al}_{2} \mathrm{O}_{3}\right)$, which can be well controlled by adjusting the EERZ volume of slag. Therefore, the simplification brought by assuming an overall diffusion coefficient of slag components can have a limited impact on the simulation results with the description of most pyrometallurgical processes using the EERZ model. When large variations in slag chemistry and temperature take place within a given process, the slag viscosity can be taken into account in the determination of the EERZ volume to have a more flexible and accurate description of the process using the EERZ model.

\section{B. Virtual Process Simulations}

The present authors have successfully applied the EERZ model to a wide range of steel production processes including Electrical Arc Furnace, ${ }^{[70]}$ hot metal treatment (powder injection), ${ }^{[71]}$ Basic Oxygen Furnace (LD-LBE with double slag operation, K-OBM), ${ }^{[72,73]}$ RH Degasser, ${ }^{[69]}$ Vacuum Tank Degasser, ${ }^{[74]}$ Ladle Furnace, ${ }^{[75]}$ Tundish, ${ }^{[76]}$ Continuous Casting, ${ }^{[77]}$ and Argon Oxygen Decarburization ${ }^{[78]}$ processes. For the development of process models, the industrial partners have provided wide range of real operation conditions and sampling data. With these precious data, the model parameters, such as the overall mass transfer coefficient 


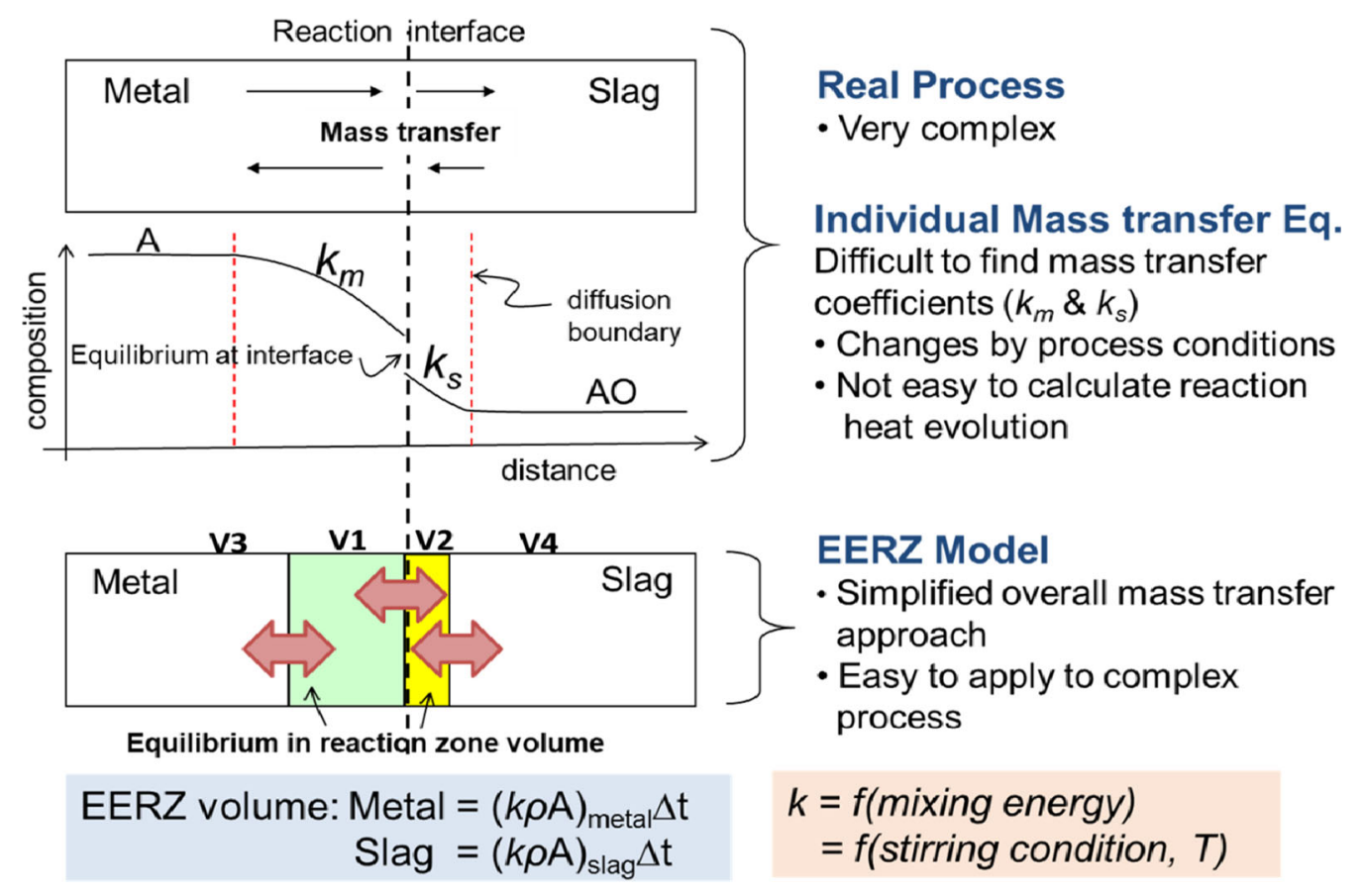

Fig. 22-Concept of Effective Equilibrium Reaction Zone (EERZ) model.

equation as a function of mixing energy, were tuned to reproduce the plant data. In all cases, FactSage databases have been used for the equilibrium calculations and FactSage Macro Processing has been utilized to build such kinetic models. In FactSage software, the Equilib program can be automated by the embedded coding called "Macro Processing". All the input conditions and calculation results can be stored and passed to the different equilibrium calculations or externally to text files or Microsoft Excel $^{\mathrm{TM}}$ files using the macro processing code. The schematics of FactSage macro processing is given in Figure 23.

As an example, the simulation model for the ladle furnace (LF) is presented in Figure 24. A first version of the LF model was introduced by Van Ende and Jung. ${ }^{[75]}$ In order to apply the original LF process model to the LF installation at Tata Steel Europe, a new reaction zone was introduced to include the observed steel reoxidation. ${ }^{[79]}$ The reoxidation phenomenon was carefully monitored using the plant data. The reoxidation rate was found to change with stirring conditions, and a sophisticated reoxidation reaction zone (R5' in Figure 1) was taken into account in the revised LF model. In order to show the accuracy and versatility of the model, the simulation results for a complex LF operation involving multiple flux additions, metallic additions, and arcing operation are presented in Figure 25. In order to check the accuracy of the model, extensive plant sampling of slag, metal and non-metallic inclusions were carried out every 2 to 3 min intervals. As can be seen in Figure 25, the simulation results from the present LF model are in very good agreement with plant data for the composition of slag, liquid steel, and non-metallic inclusion, and liquid steel temperature. It should be noted that the model results without considering steel reoxidation (dotted lines) are less accurate. The gradual $\mathrm{CaO}$ and $\mathrm{MgO}$ pickup in the inclusions is well reproduced with the present model (Figure 25(d)). The pickup originates from the reduction of very small amount of $\mathrm{CaO}$ and $\mathrm{MgO}$ from the top slag by $\mathrm{Al}$ in liquid steel at the slag/steel interface, then reoxidation of the dissolved $\mathrm{Ca}$ and $\mathrm{Mg}$ in liquid steel at the inclusions/steel interface. One of the most important elements to control in the LF process is sulfur. In order to reduce and accurately control $\mathrm{S}$ in liquid metal, a reduced slag with high basicity is prerequisite and fast reaction kinetics between slag and metal is necessary. In addition, reoxidation of steel should be minimized. Figure 26(a) shows the variation of $\mathrm{S}$ content in the operation shown in Figure 25. As can be seen, the evolution of the $\mathrm{S}$ content in plant is very well reproduced by the LF model. The present LF model was used to simulate 24 different heats with various process conditions. The comparison between simulated and calculated S content in metal for 24 heats is shown in Figure 26(b). Each point represents a sample taken during the heat. As can be seen, the model is able to reproduce accurately the evolution of the LF process under various process conditions.

\section{Smart Factory (Industry 4.0)}

Smart factory is one of commanding trends in the manufacturing industry. The steel industry is quickly adopting the smart factory concept and digital transformation. All leading steel companies collect enormous amount of data from sensors at the plant in order to analyze them and extract relationships between operation conditions and process outputs. However, upstream processes like ironmaking and steelmaking deal with 


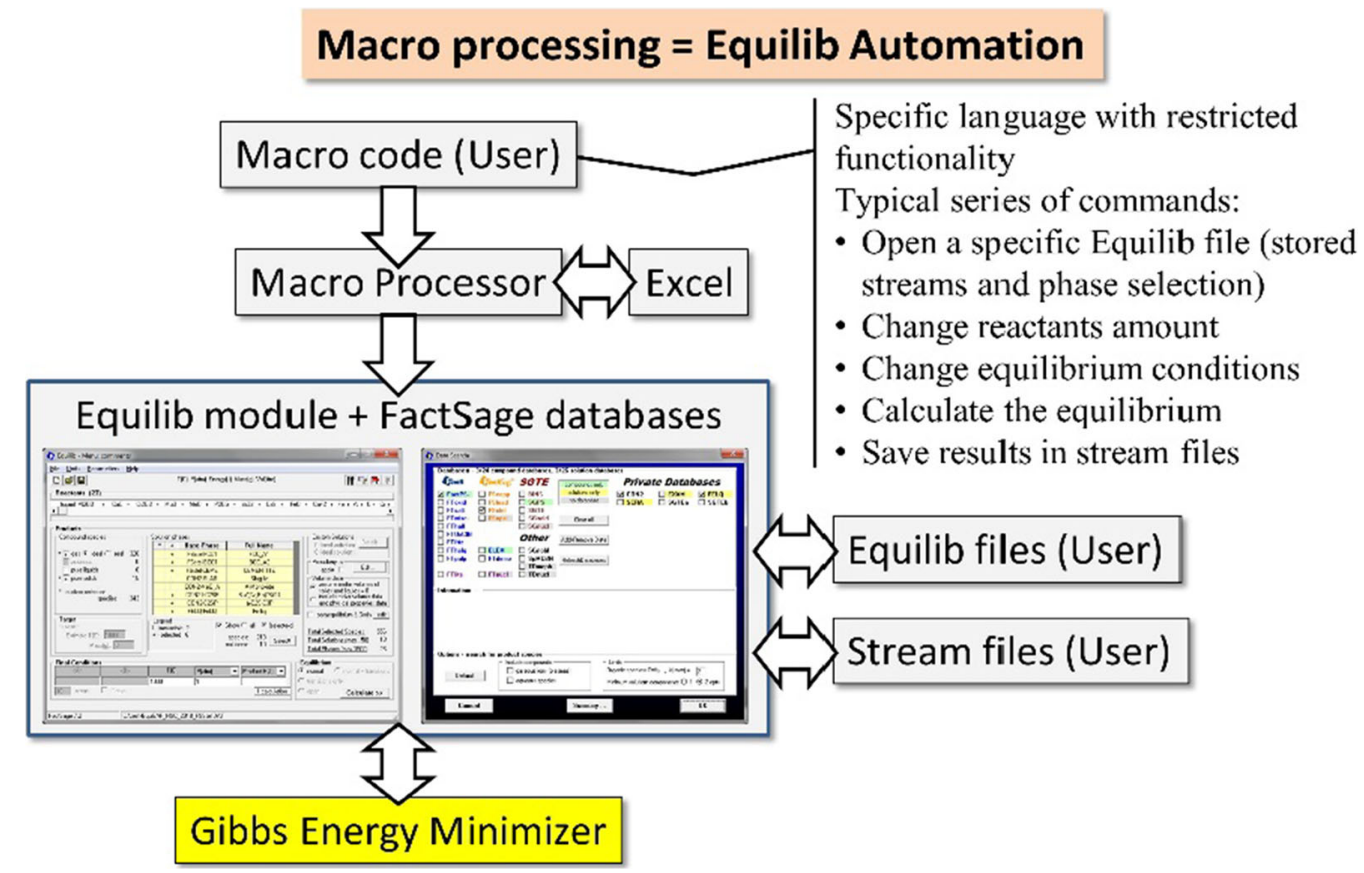

Fig. 23-Concept of FactSage macro processing.

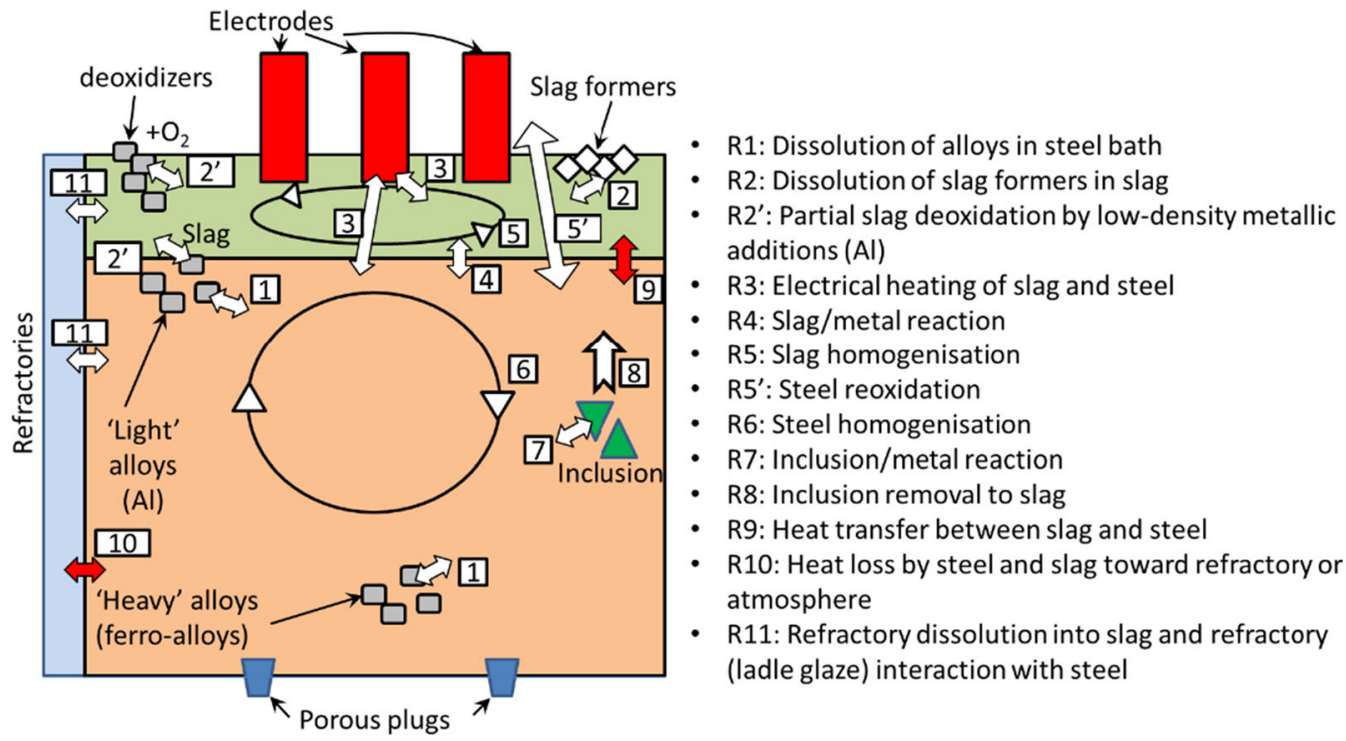

Fig. 24 Schematic diagram of reaction zones of the ladle furnace model developed for Tata Steel Europe. Figure published in the paper Applicability of the Ladle Process Model to Plant Operation; authors: Marie-Aline VAN ENDE, In-Ho JUNG and Erwin HARBERS, presented at The European Oxygen Steelmaking Conference (EOSC), Taranto, 10 to 12 October 2018 ${ }^{[79]}$ Reprinted with permission.

liquid metal at high temperatures. Due to the nature of the process, there are many uncontrollable factors in operation and noticeable scatter in the collected data, which make difficult to adopt the smart factory process. Therefore, sometimes the analysis of big data from the plant may not give the proper direction or trend due to the scatter.

There are many key components to complete a smart factory. One of the key components is the so-called digital twin, which is the digital replica of an actual plant (virtual plant simulator). In the case of the ironmaking and steelmaking process, chemical reactions between liquid metal, slag, gas, and refractory materials are the most important factors controlling the productivity and quality of the final molten metal product. Therefore, creating a digital twin accounting for accurate thermodynamics and kinetics of chemical reactions is highly necessary. A robust digital twin can provide the simulation of possible scenarios and predict possible outcomes, without affecting the physical production. Based on the real-time collected data, the digital twin 


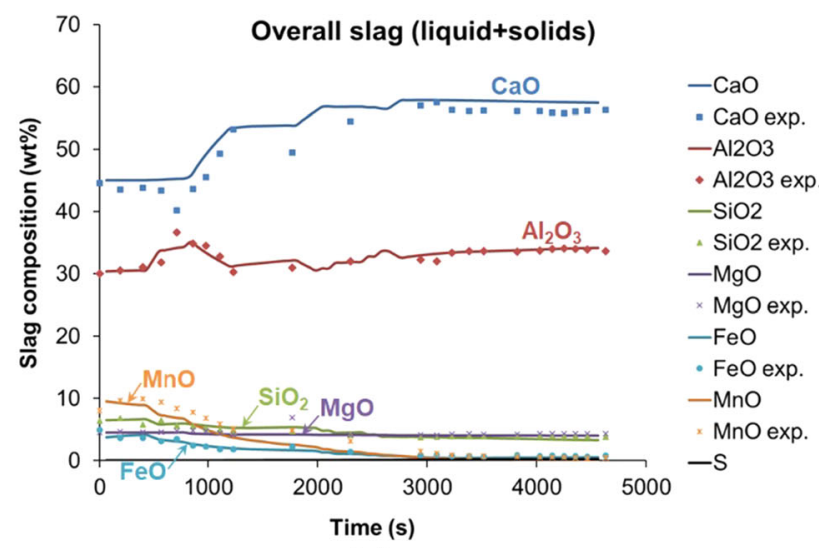

(a)

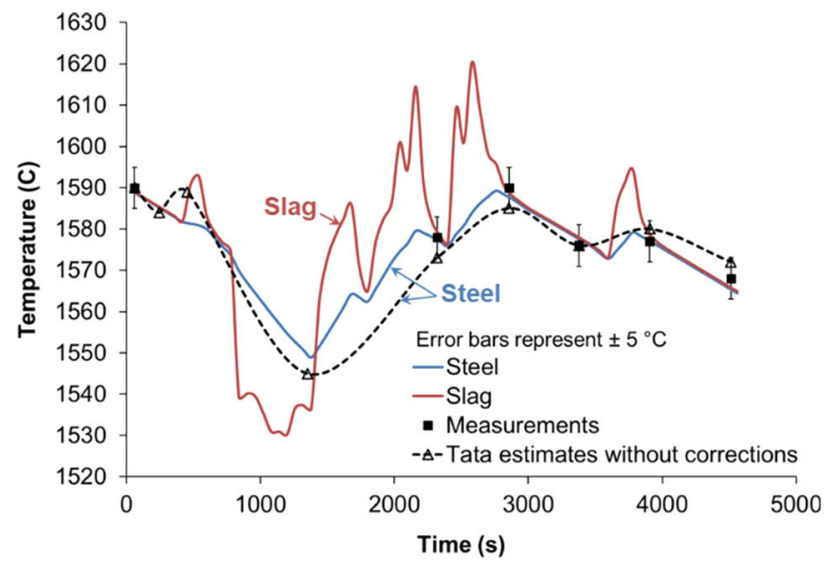

(c)

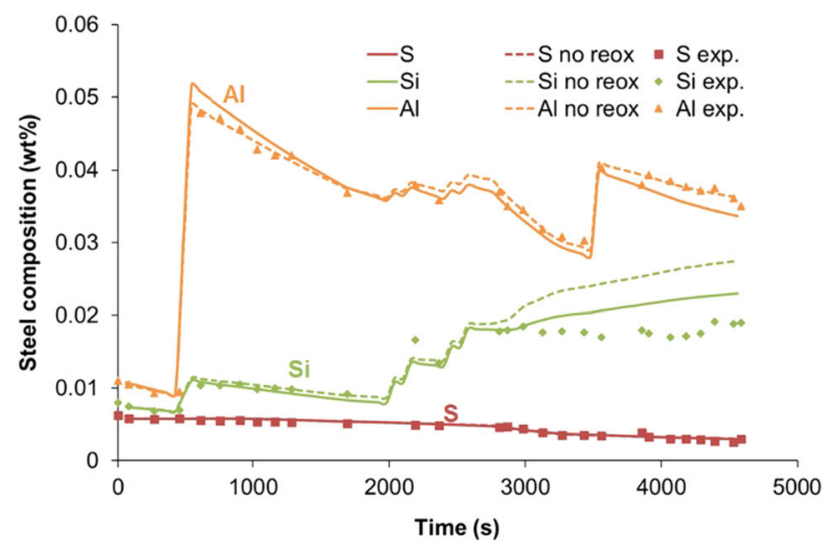

(b)

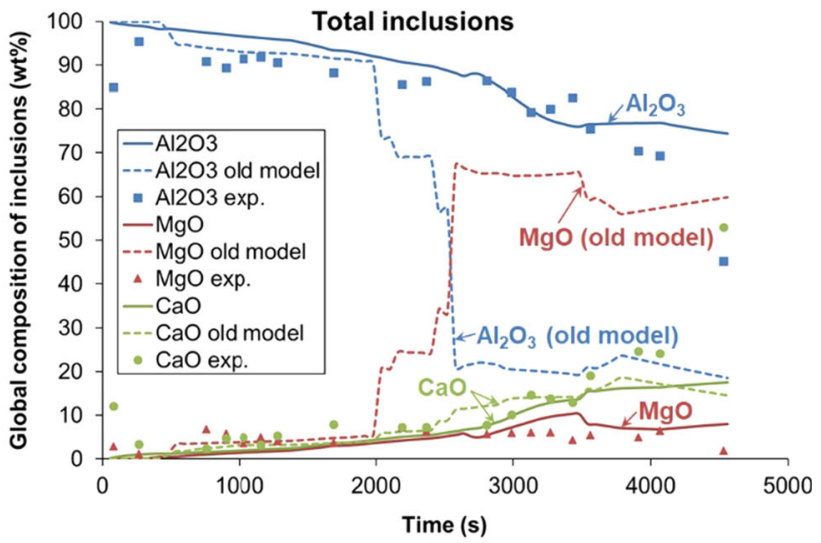

(d)

Fig. 25-Evolution of the simulation results during the LF process compared with measurements (plant data from Tata Steel Europe ${ }^{[79]}$ : $(a)$ overall slag composition (liquid + solid), (b) Al, Si and S content in steel, (c) steel and slag temperature, and (d) non-metallic inclusion composition.

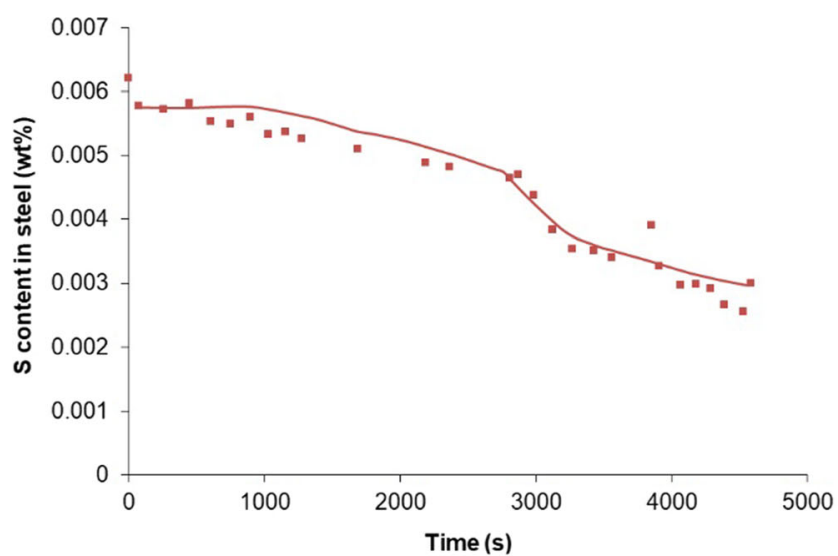

(a)

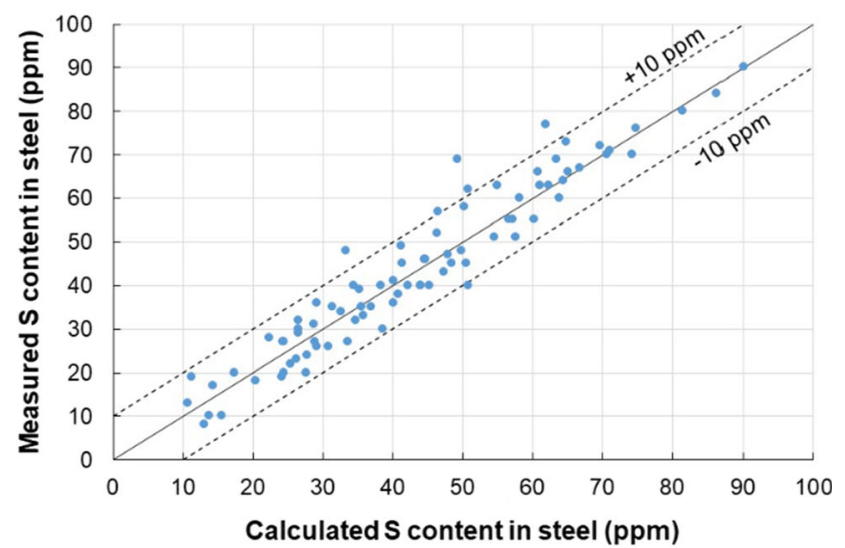

(b)

Fig. 26-(a) The variation of S content in liquid steel during LF process (line is calculated from the LF model), and (b) comparison of calculated and measured $\mathrm{S}$ content in samples taken from 24 heats. The plant data are from Tata Steel Europe ${ }^{[79]}$ 


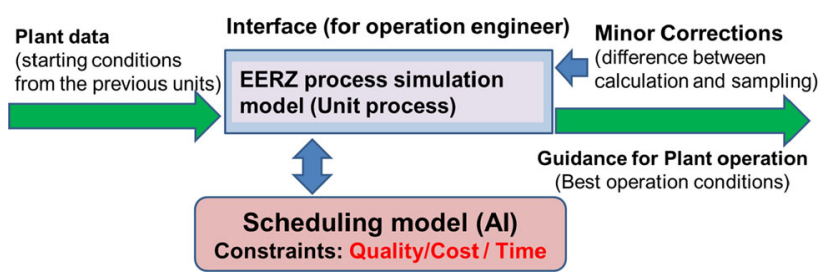

Fig. 27-Future application of a process simulation model based on EERZ model in real plant operation.

can also provide optimal process conditions, create synergy across the plant, detect defects and predict maintenance.

The process simulation model based on the EERZ concept can be a good digital twin candidate for the ironmaking and steelmaking process. Several steelmaking companies in the steelmaking consortium already use the process model as digital twin. The models provide virtual simulations for a wide range of operation conditions and chemistry. These simulation results can be used as big data for the development of level 2 control model in the plant.

As part of the steelmaking consortium project, our future direction in the development of process models is building a virtual integrated steel plant. In this virtual steel plant, all the process models based on FactSage macro processing will be converted to stand-alone models using the ChemApp DLL (https://gtt-technolog ies.de) in order to improve the simulation time. With this conversion, a 1-hour real operation process can be simulated within 5 to $10 \mathrm{~min}$, demonstrating that models based on the EERZ concept can be applied to real-time process simulation. Eventually, a virtual steel plant containing a series of process models in one platform can be automatically operated with an Artificial Intelligent (AI) control system to provide the best operation conditions under the target constraints dynamically changing depending on economic situation. After validation, it can be directly connected to the level 2 control system at the plant to provide real-time optimal operation conditions, as schematically presented in Figure 27.

\section{SUMMARY}

The FactSage thermodynamic databases covering a wide range of materials processes have been developed in close and long-term collaborations with industrial partners. A sound thermodynamic model reflecting the nature of a solution is key to accurately describe the thermodynamics of the solution phase and develop a comprehensive thermodynamic database for the solution. In FactSage, the Modified Quasichemical Model has been exclusively and successfully used for describing liquid solution phases such as molten slag, matte, salts, and even metallic phases. The bond structure calculated from the model has also been used for the development of physical property models such as viscosity, molar volume, electrical conductivity, etc.
In the present study, the current FactSage databases and on-going developments were briefly overviewed. Several application examples of the thermodynamics databases to the steel industry were covered, from iron ore sintering, alkali circulation in the blast furnace, dephosphorization in the basic oxygen furnace, secondary refining and casting process of high alloy steels, new steel grade design, to the galvanizing coating line. The on-going advancements on virtual process simulation in collaboration with steel companies were presented. These virtual process simulations based on the Effective Equilibrium Reaction Zone (EERZ) model have already been adopted for smart factory in the steel industry. The FactSage software with thermodynamic databases has also been applied in the aluminum, non-ferrous, combustion and energy industries, etc. We believe that CALPHAD-type thermodynamic databases will become more and more essential for materials research and processing in both the academic community and industrial sectors.

\section{ACKNOWLEDGMENTS}

Financial supports from Tata Steel Europe, POSCO, Hyundai Steel, Nucor Steel, RioTinto Iron and Titanium, Nippon Steel Corp., JFE Steel, Voestalpine, RHI-Magnesita, Schott A.G., Doosan Heavy Industry and Construction, and SeAh Besteel are gratefully acknowledged. This work was also supported by a grant of the National Research Foundation of Korea (NRF) funded by the government of Korea (MSIT) (No. 2020R1A5A6017701). The authors would like to express their gratitude to Tata Steel Europe for sharing their plant data, and Dr. Min-Kyu Paek, Dr. Dong-Geun Kim, and Mr. Zhimin You for their help in the preparation of the application examples.

\section{REFERENCES}

1. N. Saunders and A.P. Miodownik: CALPHAD (Calculation of Phase Diagrams): A Comprehensive Guide, Pergamon Press, New York, 1998.

2. P.J. Spencer: Calphad, 2008, vol. 32, pp. 1-8.

3. I.-H. Jung: Calphad, 2010, vol. 34, pp. 332-62.

4. J. Lehman, K. Hack, M.-A. Van Ende, E. Jak, and I.-H. Jung: Computational thermodynamics, in Treatise on Process Metallurgy: Process Phenomena, Volume 2: Process Phenomena, S. Seetharaman, A. McLean, R. Guthrie, and S. Sridhar, eds., Elsevier, Amsterdam, 2014, pp. 587-852.

5. C. Bale, E. Bélisle, P. Chartrand, S.A. Decterov, G. Eriksson, A.E. Gheribi, K. Hack, I.-H. Jung, Y.-B. Kang, J. Melançon, A.D. Pelton, S. Petersen, C. Robelin, J. Sangster, P. Spencer M.-A. Van Ende: Calphad, 2016, vol. 54, pp. 35-53.

6. A.D. Pelton: Phase Diagrams and Thermodynamic Modeling of Solutions, Elsevier, Amsterdam, 2018.

7. A.D. Pelton and M. Blander: Metall. Trans. B, 1986, vol. 17B, pp. 805-15.

8. M. Blander and A.D. Pelton: Geochim. Cosmochim. Acta, 1987, vol. 51, pp. 85-95.

9. A.D. Pelton, S.A. Decterov, G. Eriksson, C. Robelin, and Y. Dessureault: Metall. Mater. Trans. B, 2000, vol. 31B, pp. 651-60.

10. A.D. Pelton and P. Chartrand: Metall. Mater. Trans. A, 2001, vol. 32A, pp. 1355-60. 
11. P. Chartrand and A.D. Pelton: Metall. Mater. Trans. A, 2001, vol. 32A, pp. 1397-1408.

12. A.D. Pelton and P. Chartrand: Metall. Mater. Trans. A, 2001, vol. 32A, pp. 1409-16.

13. A.D. Pelton: Calphad, 2001, vol. 25, pp. 319-28.

14. P. Chartrand and A.D. Pelton: J. Phase Equilib, 2000, vol. 21, pp. $141-47$.

15. Y.-M. Muggianu, M. Gambino, and J.-P. Bros: J. Chim. Phys., 1975, vol. 72, pp. 83-88.

16. G.W. Toop: Trans. AIME, 1965, vol. 233, pp. 850-55.

17. F. Kohler: Monatsh. Chemie, 1960, vol. 91, pp. 738-40.

18. I.-H. Jung: Critical Evaluation and Thermodynamic Modeling of Phase Equilibria in Multicomponent Oxide Systems, PhD thesis, École Polytechnique, Montreal, Canada, 2003.

19. I.-H. Jung, S. Decterov, and A.D. Pelton: J. Eur. Ceram. Soc., 2005, vol. 25, pp. 313-33.

20. I.-H. Jung, S. Decterov, and A.D. Pelton: J. Phase Equilib., 2004, vol. 25 , pp. 329-45.

21. I.-H. Jung, Asia Steel Conf., 2009, Pusan Korea, paper S3-30.

22. Y.-B. Kang and A.D. Pelton: Metall. Mater. Trans. B, 2009, vol. 40B, pp. 979-94.

23. P. Chartrand and A.D. Pelton: Metall. Mater. Trans. A, 2001, vol. $32 \mathrm{~A}$, pp. $1417-30$.

24. D. Lindberg, R. Backman, and P. Chartrand: J. Chem. Therm., 2007, vol. 39, pp. 1001-21.

25. S. Cui and I.-H. Jung: Calphad, 2017, vol. 56, pp. 108-25.

26. G. Eriksson, P. Wu, M. Blander, and A.D. Pelton: Can. Metall. Quart., 1994, vol. 33, pp. 13-22.

27. J.H. Park and P.C.H. Rhee: J. Non-Cryst. Solids, 2001, vol. 282, pp. 7-14.

28. M. Kim and Y.-B. Kang: J. Phase Equilib. Diff., 2015, vol. 36, pp. $453-70$.

29. S. Cui and I.-H. Jung: Metall. Mater. Trans. A, 2017, vol. 48, pp. 1383-1401.

30. I.-H. Jung, D.H. Kang, W.J. Park, N.J. Kim, and S.H. Ahn: Calphad, 2007, vol. 31, pp. 192-200.

31. P. Waldner and A.D. Pelton: Metall. Mater. Trans. B, 2005, vol. 35B, pp. 897-907.

32. M. Hillert: J. Alloy Comp., 2001, vol. 320, pp. 161-76.

33. W.L. Bragg and E.J. Williams: Proc. R. Soc. Lond. Ser. A, 1934, vol. 145 , pp. $699-730$

34. C. Wagner: Thermodynamics of Alloys, Addison-Wesley, Reading, MA, 1962.

35. A.D. Pelton and C.W. Bale: Metall. Trans. A, 1986, vol. 17A, pp. 1211-15.

36. C.W. Bale and A.D. Pelton: Metall. Trans. A, 1990, vol. 21A, pp. 1997-2002.

37. I.-H. Jung, S.A. Decterov, and A.D. Pelton: Metall. Mater. Trans. B, 2004, vol. 35B, pp. 493-507.

38. NIST-JANAF Table, https://janaf.nist.gov/.

39. I. Barin: Thermochemical Data of Pure Substances, 3rd ed., VCH Verlagsgesellschaft mbH, New York, 1995.

40. A.D. Pelton, G. Eriksson, and J.A. Romero-Serrano: Metall. Trans. B, 1993, vol. 24B, pp. 817-25.

41. A.D. Pelton: Glastechnische Berichte, 1999, vol. 72, pp. 214-26.

42. I.-H. Jung: ISIJ Int., 2006, vol. 46, pp. 1577-86.

43. I.-H. Jung: ISIJ Int., 2006, vol. 46, pp. 1587-93.

44. A.N. Grundy, H. Liu, I.-H. Jung, S. Decterov, and A.D. Pelton: Int. J. Mater. Res., 2008, vol. 99, pp. 1185-94.

45. A.N. Grundy, I.-H. Jung, S. Dectrov, and A.D. Pelton: Int. J. Mater. Res., 2008, vol. 99, pp. 1195-1209.

46. W.-Y. Kim, A.D. Pelton, and S. Decterov: Int. J. Mater. Res., 2012, vol. 103, pp. 313-28.

47. W.-Y. Kim, A.D. Pelton, C.W. Bale, E. Belisle, and S.A. Decterov: J. Min. Metall. Sect. B, 2013, vol. 49, pp. 323-37.

48. W.-Y. Kim: Modeling viscosity of molten slags and glasses, $\mathrm{PhD}$ thesis, École Polytechnique, Montreal, Canada, 2011.

49. E. Thibodeau, A. Gheribi, and I.-H. Jung: Metall. Mater. Trans. $B, 2016$, vol. 47 , pp. 1147-64.
50. E. Thibodeau, A. Gheribi, and I.-H. Jung: Metall. Mater. Trans. $B$, 2016, vol. 47, pp. 1165-86.

51. E. Thibodeau, A. Gheribi, and I.-H. Jung: Metall. Mater. Trans. B, 2016, vol. 47B, pp. 1187-1202.

52. C. Robelin, P. Chartrand, and G. Eriksson: Metall. Mater. Trans. B, 2007, vol. 38B, pp. 869-79.

53. Y.-B. Kang, C. Aliravci, P.J. Spencer, G. Eriksson, C.D. Fuerst, P. Chartrand, and A.D. Pelton: JOM, 2009, vol. 61 (5), pp. 75-82.

54. E. Thibodeau and I.-H. Jung: Metall. Mater. Trans. B, 2016, vol. 47B, pp. 355-83.

55. E.R. Thibodeau: Modeling the Molar Volume and Electrical Conductivity of Oxide Melts, Master thesis, 2015, McGill University, Canada.

56. I.-H. Jung, S. Decterov, and A.D. Pelton: ISIJ Int., 2004, vol. 44, pp. 527-36.

57. M. Rigaud, J. Smith, I.-H. Jung, and J. Poirier:Thermodynamics, in FIRE Compendium Series Volume 2A: Corrosion of Refractories: The Fundamentals, J. Poirier and M. Rigaud, eds., Goller Verlag, Baden-Baden, 2017.

58. FIRE Compendium Series Volume 2C: Corrosion of Refractories: The impact of Corrosion, J. Poirier and M. Rigaud, eds., Goller Verlag, 2019.

59. I.-H. Jung, M.-A. Van Ende, M.-K. Cho, and Z. Cao: China's Refract., 2015, vol. 24, pp. 15-21.

60. I.-H. Jung, P. Hudon, W.-Y. Kim, M.-A. Van Ende, M. Rahman, and G. Garcia Curiel: High Temp. Mater. Process, 2013, vol. 32, pp. $247-54$

61. M.-K. Paek, K.-H. Do, Y.-B. Kang, I.-H. Jung, and J.-J. Pak: Metall. Mater. Trans. B, 2016, vol. 47B, pp. 2837-47.

62. S. Panda and I.-H. Jung: ISIJ Int., 2020, vol. 60, pp. 31-41.

63. J.-H. Lee, M.-H. Kang, S.-K. Kim, and Y.-B. Kang: ISIJ Int., 2018, vol. 58, pp. 1257-66.

64. M.-K. Paek, S. Chatterjee, and I.-H. Jung: Metall. Mater. Trans. B, 2016, vol. 47B, pp. 1243-62.

65. S.-H. Kim, H. Kim, and N.J. Kim: Nature, 2015, vol. 518, pp. 7779.

66. N. Shimoda, Y. Kubo, and K. Ueda, Nippon Steel \& Sumitomo Metal Technical Report, 2015, No. 108, pp. 60-63.

67. Zagnelis: trademark, Arcelor-Mittal.

68. I.-H. Jung, M. Paliwal, Y.-M. Kim, S.-K. Lee and J.-S. Kim, Asia-Pacific Galvanizing Conference, 2009, Jeju Island, paper \# A-34.

69. M.-A. Van Ende, Y.-M. Kim, M.-K. Cho, J.H. Choi, and I.-H. Jung: Metall. Mater. Trans. B, 2011, vol. 42B, pp. 477-89.

70. M.-A. Van Ende and I.-H. Jung: Process Simulation Model for Electrical Arc Furnace, 2018 FactSage Steelmaking Consortium Project, Seoul, 2018.

71. E. Moosavi-Khoonsari, M.-A. Van Ende and I.-H. Jung, 7th ICS, 2018, Venice, Italy, Code 144934.

72. M.-A. Van Ende and I.-H. Jung: CAMP-ISIJ, 2015, vol. 28, pp. 527-30.

73. M.-A. Van Ende, and I.-H. Jung, Asia Steel 2015, pp. 596-597.

74. M.-K. Paek and I.-H. Jung: Process Simulation Model for Vacuum Tank Degassor, 2015 FactSage Steelmaking Consortium Project, Montreal, 2015.

75. M.-A. Van Ende and I.-H. Jung: Metall. Mater. Trans. B, 2017, vol. 48B, pp. 28-36.

76. M.-A. Van Ende and I.-H. Jung: Process Simulation Model for Tundish, 2019 FactSage Steelmaking Consortium Project, Seoul, 2019.

77. M.-A. Van Ende and I.-H. Jung: ISIJ Int., 2014, vol. 54, pp. 48995.

78. M.-A. Van Ende and I.-H. Jung, unpublished work, 2019.

79. M.-A. Van Ende, I.-H. Jung, and E. Harbers, 8th European Oxygen Steelmaking Conference (EOSC 2018), 2018, EOSC \#030.

Publisher's Note Springer Nature remains neutral with regard to jurisdictional claims in published maps and institutional affiliations. 